Cochrane Database of Systematic Reviews

\title{
Low-molecular-weight heparins or heparinoids versus standard unfractionated heparin for acute ischaemic stroke (Review)
}

Sandercock PAG, Leong TS

Sandercock PAG, Leong TS.

Low-molecular-weight heparins or heparinoids versus standard unfractionated heparin for acute ischaemic stroke.

Cochrane Database of Systematic Reviews 2017, Issue 4. Art. No.: CD000119.

DOI: 10.1002/14651858.CD000119.pub4.

www.cochranelibrary.com 
TABLE OF CONTENTS

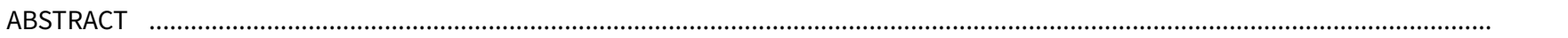

PLAIN LANGUAGE SUMMARY

SUMMARY OF FINDINGS

BACKGROUND

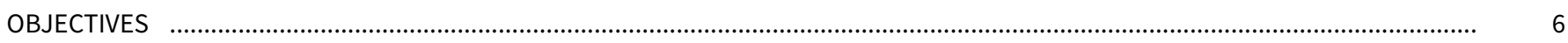

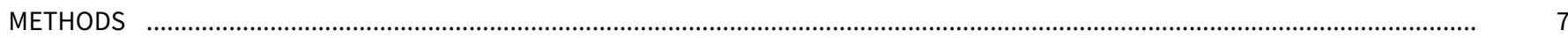

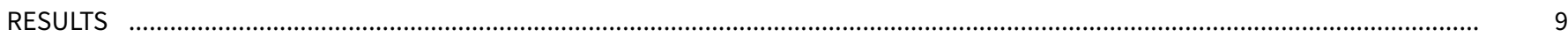

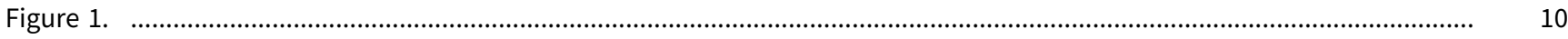

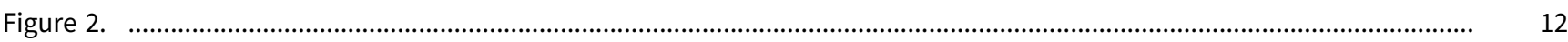

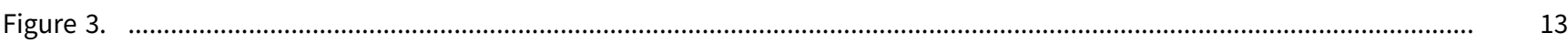

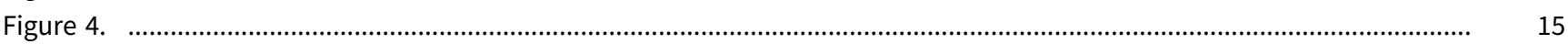

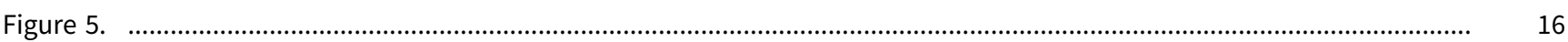

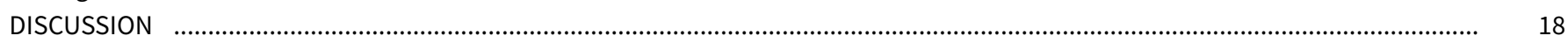

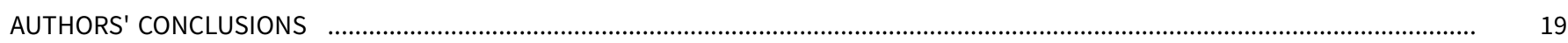

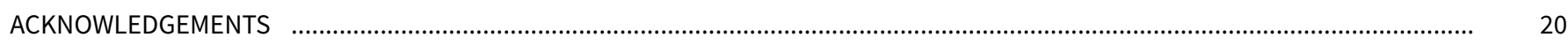

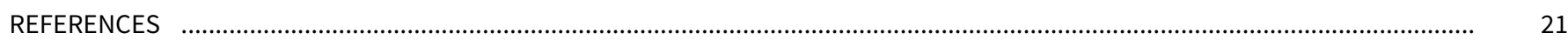

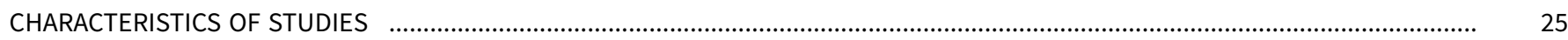

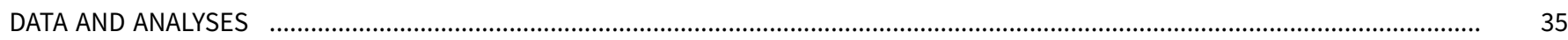

Analysis 1.2. Comparison $1 \mathrm{LMWH}$ /heparinoid versus standard UFH in acute ischaemic stroke, Outcome 2 Death from all causes 38

during treatment period.

Analysis 1.3. Comparison $1 \mathrm{LMWH}$ /heparinoid versus standard UFH in acute ischaemic stroke, Outcome 3 Death from all causes during follow-up.

Analysis 1.4. Comparison $1 \mathrm{LMWH}$ /heparinoid versus standard UFH in acute ischaemic stroke, Outcome 4 Vascular death during follow-up.

Analysis 1.5. Comparison $1 \mathrm{LMWH}$ /heparinoid versus standard UFH in acute ischaemic stroke, Outcome 5 Deep venous thrombosis during treatment period.

Analysis 1.6. Comparison $1 \mathrm{LMWH}$ /heparinoid versus standard UFH in acute ischaemic stroke, Outcome 6 Pulmonary embolism during follow-up.

Analysis 1.7. Comparison $1 \mathrm{LMWH}$ /heparinoid versus standard UFH in acute ischaemic stroke, Outcome 7 Any intracranial haemorrhage/haemorrhagic transformation of the cerebral infarct during treatment period.

Analysis 1.8. Comparison $1 \mathrm{LMWH}$ /heparinoid versus standard UFH in acute ischaemic stroke, Outcome 8 Symptomatic intracranial haemorrhage/haemorrhagic transformation of the infarct during treatment period.

Analysis 1.9. Comparison $1 \mathrm{LMWH}$ /heparinoid versus standard UFH in acute ischaemic stroke, Outcome 9 Extracranial haemorrhage during treatment period.

Analysis 1.10. Comparison $1 \mathrm{LMWH}$ /heparinoid versus standard UFH in acute ischaemic stroke, Outcome 10 Effect of recurrent ischaemic stroke or recurrent stroke of unknown pathological type during treatment period.

Analysis 1.11. Comparison $1 \mathrm{LMWH}$ /heparinoid versus standard UFH in acute ischaemic stroke, Outcome 11 Deep venous thrombosis according to heparinoid dosage regimen.

Analysis 1.12. Comparison $1 \mathrm{LMWH}$ /heparinoid versus standard UFH in acute ischaemic stroke, Outcome 12 Intracranial and extracranial haemorrhage during treatment according to dosage regimen.

APPENDICES

FEEDBACK

WHAT'S NEW

HISTORY

CONTRIBUTIONS OF AUTHORS

DECLARATIONS OF INTEREST

SOURCES OF SUPPORT

DIFFERENCES BETWEEN PROTOCOL AND REVIEW

INDEX TERMS

.

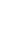

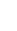

(1)

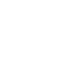
(1) (1) 5 16 18 19 1

5


[Intervention Review]

\section{Low-molecular-weight heparins or heparinoids versus standard unfractionated heparin for acute ischaemic stroke}

Peter AG Sandercock ${ }^{1}$, Tze Shin Leong²

1Centre for Clinical Brain Sciences (CCBS), University of Edinburgh, Edinburgh, UK. 2University of Edinburgh, Edinburgh, UK

Contact: Peter AG Sandercock, Centre for Clinical Brain Sciences (CCBS), University of Edinburgh, The Chancellor's Building, 49 Little France Crescent, Edinburgh, EH16 4SB, UK. peter.sandercock@ed.ac.uk.

Editorial group: Cochrane Stroke Group.

Publication status and date: New search for studies and content updated (no change to conclusions), published in Issue 4, 2017.

Citation: Sandercock PAG, Leong TS. Low-molecular-weight heparins or heparinoids versus standard unfractionated heparin for acute ischaemic stroke. Cochrane Database of Systematic Reviews 2017, Issue 4. Art. No.: CD000119. DOI: 10.1002/14651858.CD000119.pub4.

Copyright @ 2017 The Cochrane Collaboration. Published by John Wiley \& Sons, Ltd.

\section{A B S T R A C T}

\section{Background}

Low-molecular-weight heparins (LMWHs) and heparinoids are anticoagulants that may have more powerful antithrombotic effects than standard unfractionated heparin (UFH) but a lower risk of bleeding complications. This is an update of the original Cochrane Review of these agents, first published in 2001 and last updated in 2008.

\section{Objectives}

To determine whether antithrombotic therapy with LMWHs or heparinoids is associated with a reduction in the proportion of people who are dead or dependent for activities in daily living compared with UFH.

\section{Search methods}

We searched the Cochrane Stroke Group Trials Register (last searched February 2017), the Cochrane Central Register of Controlled Trials (CENTRAL: the Cochrane Library Issue 1, 2017), MEDLINE (1966 to February 2017), and Embase (1980 to February 2017). We also searched trials registers to February 2017: ClinicalTrials.gov, EU Clinical Trials Register, Stroke Trials Registry, ISRCTN Registry and the World Health Organization (WHO) International Clinical Trials Registry Platform.

\section{Selection criteria}

Unconfounded randomised trials comparing LMWH or heparinoids with standard UFH in people with acute ischaemic stroke, in which participants were recruited within 14 days of stroke onset.

\section{Data collection and analysis}

Two review authors independently chose studies for inclusion, assessed risk of bias and trial quality, extracted and analysed the data. Differences were resolved by discussion.

\section{Main results}

We included nine trials involving 3137 participants. We did not identify any new trials for inclusion in this updated review. None of the studies reported data on the primary outcome in sufficient detail to enable analysis for the review. Overall, there was a moderate risk of bias in the included studies. Compared with UFH, there was no evidence of an effect of LMWH or heparinoids on death from all causes during the treatment period (96/1616 allocated LMWH/heparinoid versus $78 / 1486$ allocated UFH; odds ratio (OR) $1.06,95 \%$ CI 0.78 to 1.47 ; 8 trials, 3102 participants, low quality evidence). LMWH or heparinoid were associated with a significant reduction in deep vein thrombosis (DVT) compared with UFH (OR $0.55,95 \% \mathrm{Cl} 0.44$ to $0.70,7$ trials, 2585 participants, low quality evidence). However, the number of the major clinical events such as pulmonary embolism (PE) and intracranial haemorrhage was too small to provide a reliable estimate of the effects. 


\section{Authors' conclusions}

Treatment with a LMWH or heparinoid after acute ischaemic stroke appears to decrease the occurrence of DVT compared with standard UFH, but there are too few data to provide reliable information on their effects on other important outcomes, including functional outcome, death and intracranial haemorrhage.

\section{PLAIN LANGUAGE SUMMARY}

Which types of blood-thinning drugs (anticoagulants) are best to prevent blood clots in people soon after stroke?

\section{Review question}

This review aimed to find out which type of blood-thinning drug works best for preventing blood clots in people who have recently had a stroke due to blockage of an artery in the brain.

\section{Background}

Stroke is a common and disabling disease. Sudden blockage of an artery to the brain, often caused by a blood clot, is the cause of the most common type of stroke. This type is called an ischaemic stroke. Anticoagulants (blood-thinning drugs), are widely used in people with stroke. As stroke is a medical emergency, and medicines given in an emergency need to reach the bloodstream quickly, these are given by injection. Injectable anticoagulants that have been tested in stroke are unfractionated heparin (UFH), low-molecular-weight heparins (LMWH), and heparinoids. These agents may help clear blocked arteries, prevent re-blockage, and prevent clots forming in leg veins (deep vein thrombosis, DVT) after an ischaemic stroke and so might prevent fatal or disabling complications of stroke and improve the chance of a good recovery. However, they can also cause harmful bleeding complications that can offset any benefits.

\section{Search date}

The search was updated to February 2017.

\section{Study characteristics}

We looked for randomised controlled trials in people with recent onset of stroke symptoms that compared LMWH or heparinoids with UFH.

\section{Key results}

We found nine trials involving 3137 participants; overall these trials had a moderate risk of bias (this means that the results are likely to be less credible than if the risk of bias was low). No new trials were included in this updated review. None of the studies reported reliable information on disability or recovery after stroke. Compared with UFH, there was no evidence of an effect of LMWH or heparinoids on death from all causes during the treatment period (quality of the evidence was low). Although LMWH or heparinoid were associated with significantly fewer clots in leg veins (DVT) than UFH, the number of major events such as when a blood clot becomes lodged in an artery in the lung (pulmonary embolism) and bleeding inside the skull (intracranial haemorrhages) was too small to know whether the harms outweighed the benefits. For people with ischaemic stroke who need immediate treatment with anticoagulants, evidence from the included clinical trials did not provide reliable evidence on the balance of risk and benefit for each type of heparin. Additional large scale research would be needed to resolve this uncertainty.

\section{Quality of the evidence}

Overall, there was a moderate risk of bias in the included studies. Using GRADE criteria we found that evidence quality was low overall. 


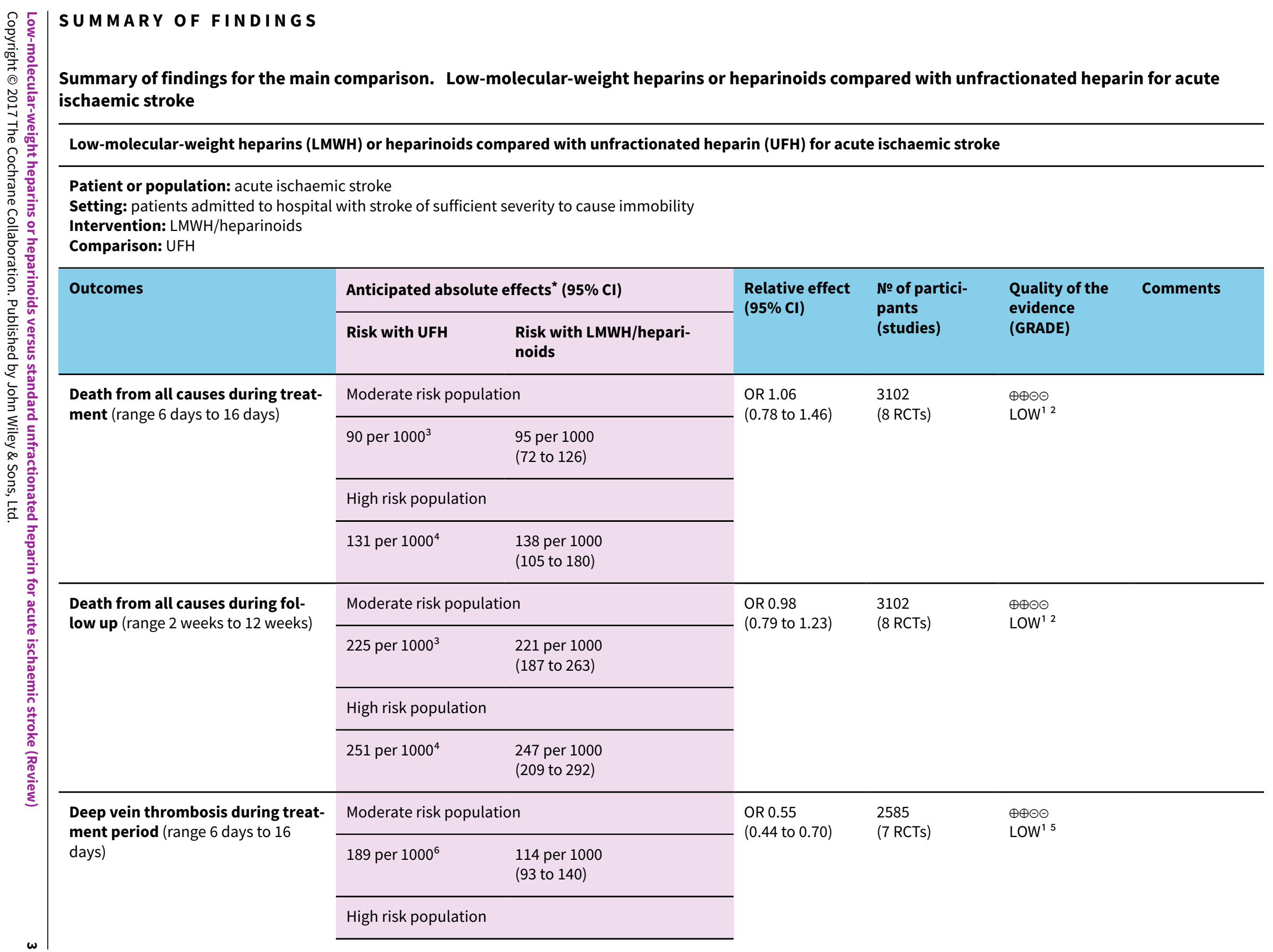




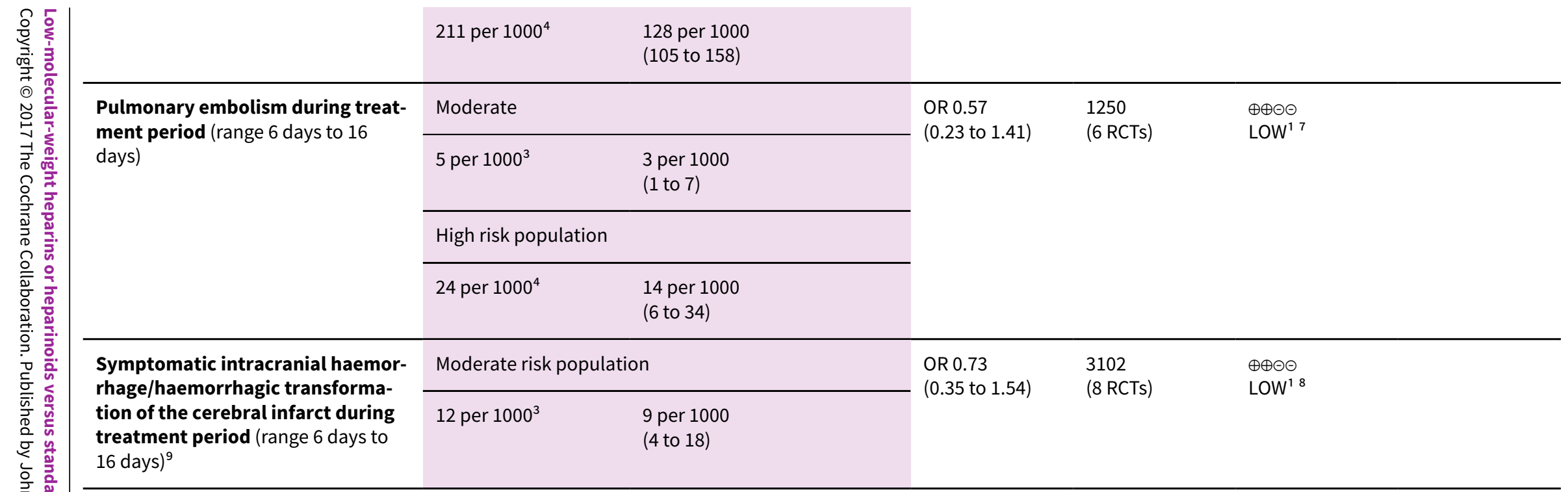

*The risk in the intervention group (and its 95\% confidence interval) is based on the assumed risk in the comparison group and the relative effect of the intervention (and its $95 \% \mathrm{Cl}$ ).

CI: Confidence interval; RR: Risk ratio; OR: Odds ratio; RCT: randomised controlled trial; LWMH: low-molecular-weight heparin; UFH: unfractionated heparin

\section{GRADE Working Group grades of evidence}

High quality: We are very confident that the true effect lies close to that of the estimate of the effect

Moderate quality: We are moderately confident in the effect estimate: The true effect is likely to be close to the estimate of the effect, but there is a possibility that it is substantially different

Low quality: Our confidence in the effect estimate is limited: The true effect may be substantially different from the estimate of the effect

Very low quality: We have very little confidence in the effect estimate: The true effect is likely to be substantially different from the estimate of effect

1 There were unclear risk of selection bias in Hageluken 1992, Dumas 1994, Stiekema 1988, TRACE 2004, Turpie 1992 and Wong 2000. Hageluken 1992 and Stiekema 1988 were single blinded studies; PREVAIL 2007 was an open label study. Hence, making all these study high risk of performance and detection bias (downgraded 1 level).

${ }^{2}$ Small number of deaths were recorded throughout studies (downgraded 1 level).

${ }^{3}$ Calculated based on control event rate from IST 1997 where based on the inclusion criteria, it was interpreted that people are of average risk (hence, they are classified as 'moderate risk population') of developing complications such as deep vein thrombosis (DVT), pulmonary embolism (PE), cranial haemorrhages etc. that resulted in death or disability.

[ Calculated based on control event rate from CLOTS3 2015 trial where based on the inclusion criteria, people are of high risk (hence they are classified as 'high risk population') of developing complications such as DVT, PE, cranial haemorrhages that resulted in death or disability.

${ }^{5}$ Methods of detection of detection of DVT were variable across the studies (downgraded 1 level).

${ }^{6}$ Calculated based on mean baseline risk from the studies of this Cochrane Review because IST 1997 did not include this outcome data.

${ }^{7}$ Small number of PEs across the studies.

${ }^{8}$ Small number of symptomatic intracranial haemorrhage across studies.

$\rightarrow$

${ }^{9}$ High risk population not available as CLOTS3 2015 trial did not include this outcome data. 


\section{B A C K G R O U N D}

Low-molecular-weight heparins (LMWHs) and heparinoids are anticoagulants that may have more powerful antithrombotic effects than standard unfractionated heparin (UFH) but a lower risk of bleeding complications. This is an update of the Cochrane Review Low-molecular-weight heparins or heparinoids versus standard unfractionated heparin for acute ischaemic stroke, first published in 2001 (Counsell 2001) and last updated in 2008 (Sandercock 2008).

\section{Description of the condition}

Worldwide, stroke is one of the most common causes of death and disability in both developed and developing countries (Lozano 2012). Four-fifths of all strokes are caused by reduction in, or blockage of, blood flow in the artery supplying a particular part of brain; this type of stroke is called an ischaemic stroke (Warlow 2008). A common cause of ischaemic stroke is a blood clot that developed in the heart or large arteries travelling through the circulation to block a brain blood vessel (Caplan 2009).

\section{Description of the intervention}

Anticoagulants act on different components of the coagulation system to reduce fibrin and thrombus formation (Holbrook 2012). Some anticoagulants, such as Vitamin K antagonists, can only be given by mouth, have a slow onset of action, and so are not suitable for use as an emergency treatment in acute stroke where prompt onset of effect is needed and where difficulty swallowing from the stroke may preclude oral administration. The anticoagulant agents that have commonly been used in people with stroke that can be given parenterally and have a rapid onset of action are unfractionated heparin (UFH), low-molecular-weight heparins (LMWHs) and heparinoids (Sandercock 2015). Standard UFH is a sulphated polysaccharide that affects the coagulation pathway by inhibition of Factor Xa and thrombin activity (Choay 1989; Cruickshank 1991). LMWHs are smaller molecules derived from heparin and act predominantly to inhibit Factor Xa (Cella 1986; Gordon 1990; Weitz 1997). Heparinoids are aminoglycans that inhibit thrombin activity via activation of the effect of heparin co-factor 2 (Shorr 2008). LMWHs and heparinoids have better bioavailability and longer half-life compared with UFH (Garcia 2012; Meuleman 1992).

\section{How the intervention might work}

In people with ischaemic stroke who arrive in hospital within the first few hours of onset, anticoagulants may be used as an emergency treatment to help dissolve the blood clot blocking the cerebral vessel, or to prevent new blood clots forming in arteries or veins. Early use of anticoagulants in acute ischaemic stroke might therefore have several beneficial effects: to reduce cerebral damage from the initial stroke, prevent early recurrent ischaemic stroke, and prevent venous thromboembolic events (VTES) (IST 1997). VTEs include deep vein thrombosis (DVT, a blood clot lodging in a deep vein of the leg) and pulmonary embolism (PE, a blood clot lodging in an artery in the lungs). These actions of anticoagulants might reduce the chance of death from vascular causes, increase the chance of neurological recovery, and so improve the person's overall clinical outcome after acute ischaemic stroke (Sandercock 2015).

\section{Why it is important to do this review}

Randomised trials comparing UFH, LMWH, and heparinoids with placebo have not provided any convincing evidence that these agents improve survival or functional outcome of people with acute ischaemic stroke (IST 1997; Sandercock 2015; TOAST 1998). This is probably because any reductions in early recurrent ischaemic stroke or PE were offset by similar-sized increases in intra- and extracranial haemorrhages (bleeding inside and outside the brain). There was no difference in the overall clinical outcome, at final follow up as measured by the proportion of people dead or dependent at the end of follow-up (IST 1997; Sandercock 2015; TOAST 1998).

However, the Cochrane Review of the randomised trials comparing anticoagulant regimens with control in acute ischaemic stroke showed that anticoagulant therapy significantly reduced the odds of DVT by about $66 \%$, from a rate of about $44 \%$ in those allocated to control, to $15 \%$ in those allocated to anticoagulants (Gubitz 2004; Sandercock 2015). There was also a significant $36 \%$ reduction in the odds of PE with anticoagulants. Hence, clinicians may still wish to consider the use of heparin in low dose for the prevention of DVT and life threatening PE.

The coagulation cascades are inhibited non-specifically at a number of different sites by standard UFH. It also inhibits platelet function (Choay 1989). These multiple blood thinning effects may increase the potential for UFH to cause haemorrhage (Gordon 1990), and so anticoagulant agents with more specific sites of action may be associated with lower risks of haemorrhage. Two such classes of agents are LMWHs and heparinoids. LMWHs and heparinoids have a more powerful antithrombotic effect than UFH and they also have a much longer half-life (period for which a drug actively affects the body) (Gordon 1990; Meuleman 1992). Although, from the described pharmacodynamics and pharmacokinetics, LMWHs and heparinoids should be safer to use in acute stroke than UFH, a systematic review of trials of LMWH with control suggested the greater antithrombotic efficacy was offset by greater bleeding risk (Bath 2000).

Previous reviews of anticoagulants versus control provided only indirect comparisons of the safety and efficacy of the different agents and such indirect comparisons are prone to bias (Gubitz 2004; Sandercock 1993). Only trials providing a direct randomised comparison of LMWHs or heparinoids with UFH will provide an unbiased assessment of the risk of haemorrhage, vascular death, and the effect on overall clinical outcome. Hence, a Cochrane Review of all the randomised trials directly comparing LMWHs or heparinoids with UFH to provide an unbiased assessment of the merits of each agent was first published in 2005 and updated in 2008. In our view, since high dose heparin is still occasionally used as a treatment for stroke (Chung 2016) and low-dose heparins are still used for prevention of DVT and PE in up to $40 \%$ of people with stroke in the USA (Amin 2013), an update was required to determine whether there were any new trials that may potentially change the conclusions of the previous review.

\section{O B J E C T IVES}

- Primary: to determine whether antithrombotic therapy with low-molecular-weight heparins (LMWH) or heparinoids is associated with a reduction in the proportion of people who are 
dead or dependent for activities in daily living compared with unfractionated heparin (UFH).

- Secondary: to determine whether, compared with UFH antithrombotic therapy with LMWHs or heparinoids is associated with:

- a difference in deaths;

- a lower incidence of deep vein thrombosis (DVT) and pulmonary embolism (PE) compared with UFH;

- a reduction of the risk of early recurrent ischaemic strokes compared with UFH;

- an increased risk of fatal or disabling intracranial or extracranial haemorrhage.

Note: the previous versions of this Cochrane Review did not specify a primary outcome, but sought to compare the effects of $\mathrm{LMWH}$ and heparinoids and UFH across a range of outcomes. When this update was planned we defined the primary objective and the primary outcome to be consistent with other Cochrane Stroke Reviews, since the proportion of people who are dead or dependent for activities in daily living provides a single outcome that captures the net longer-term effect on the person of the benefits and harms of this short-term treatment.

\section{METHODS}

\section{Criteria for considering studies for this review}

\section{Types of studies}

We included all unconfounded and truly randomised trials in this Cochrane Review. In these trials, the use of low-molecularweight heparins (LMWH) or heparinoids in the acute phase of ischaemic stroke was compared with standard unfractionated heparin (UFH) as control. We did not include randomised trials in which the method of allocation to treatment or control group was not adequately concealed (e.g. allocation by alternation, date of birth, hospital number, day of the week, or open random number list). This is because foreknowledge of treatment allocation might lead to biased allocation (Odgaard-Jensen 2011) and hence to misleading estimates of treatment effect.

\section{Types of participants}

We excluded trials that randomised people more than 14 days after onset of the stroke and trials in people with only transient ischaemic attacks because this Cochrane Review was confined to early treatment of acute stroke. It was not essential for all people to have computed tomography (CT) scanning before entry to the trial (we were interested in people with confirmed or presumed ischaemic stroke), but we excluded trials which only included people with definite haemorrhagic stroke (stroke due to bleeding in the brain rather than blockage of an artery).

\section{Types of interventions}

Trials that compared a LMWH or heparinoid possessing anticoagulant activity with UFH were eligible. The UFH was administered either as a low dose subcutaneous regimen or a high dose intravenous one.

The heparinoids currently available included: Org 10172/ danaparoid (Orgaran), dermatan sulphate, mesoglycan, and pentosan polysulphate. The LMWHs or heparinoids were administered either intravenously or subcutaneously. We identified all trials, irrespective of whether the purpose of therapy was to prevent deep vein thrombosis (DVT) and pulmonary embolism (PE), to reduce neurological disability, or to reduce the risk of early recurrent ischaemic stroke.

The LMWHs currently available included: Kabi 2165/dalteparin (Fragmin); CY 216/nadroparin (Fraxiparine); CY 222; PK 10169/ enoxaparin (Clexane/Lovenox); LHN-1/tinzaparin (Logiparin/ Innohep); OP 2123/parnaparin (Fluxum); certoparin (Sandoparin); reviparin (Clivarine); and Sandoz LMWH.

\section{Types of outcome measures}

We aimed to extract from each trial the number of people originally allocated to each treatment group, and, in each treatment group, the number of people with the following outcome events.

\section{Primary outcomes}

To be consistent with current methodological guidance from the Cochrane Stroke Group Editorial Board, we defined a primary outcome for this update of the review. In previous versions, we had defined 10 outcomes, and did not specify a single primary outcome. For this update, from the previous list of 10 outcomes, we chose 'the proportion of people who had died or needed help with daily activities at six months after randomisation' as the most clinically relevant of the 10 as the primary and we then classed the remaining nine as secondary outcomes.

\section{Secondary outcomes}

- Death from any cause during the scheduled treatment period.

- Death from any cause during the scheduled follow-up period.

- Death from vascular causes during the scheduled treatment and follow-up period. We defined vascular death (i.e. definitely or possibly vascular) as any death due to stroke (including complications of immobility resulting from the stroke e.g. pneumonia) or due to cardiac, haemorrhagic, embolic, or other vascular causes.

- Objective evidence of the occurrence of DVT detected by a systematically applied method (i.e. I125 fibrinogen scanning, doppler ultrasound or systematic X-ray contrast venography) in all surviving participants during the scheduled treatment period (the detection of DVT after the treatment period tended to be non-systematic and therefore potentially biased).

- Participants with at least one confirmed PE diagnosed during the scheduled follow-up period, or at autopsy.

- Participants with any intracranial haemorrhage or haemorrhagic transformation of the cerebral infarct confirmed by systematic $\mathrm{CT}$ or magnetic resonance (MR) scanning at the end of the treatment period, or by autopsy.

- Participants with symptomatic intracranial haemorrhage or haemorrhagic transformation of the cerebral infarct (dead brain tissue) confirmed by CT or MR scanning after clinical deterioration, or by autopsy.

- Participants with any major or minor extracranial haemorrhage. The definition of major haemorrhage was usually taken from the original article but if none was given we defined it as any bleed resulting in death, transfusion or operation.

- Participants with a recurrent stroke during the scheduled treatment period that was either definitely ischaemic (haemorrhage excluded on CT or MR scan or at autopsy) or in 
which the pathology was unknown because no CT or MR or autopsy was performed.

\section{Search methods for identification of studies}

See the 'Specialized register' section in the Cochrane Stroke Group module. We attempted to identify all relevant trials regardless of language or publication status, and arranged translation of relevant papers where necessary.

\section{Electronic searches}

With the assistance of the Managing Editor, we searched the Cochrane Stroke Group Trials Register (date last searched 6 February 2017). In addition, we searched the following bibliographic databases and trial registers.

- Cochrane Central Register of Controlled Trials (CENTRAL 2017, Issue 1) in the Cochrane Library (searched February 2017, Appendix 1);

- MEDLINE in Ovid (searched February 2017, Appendix 2);

- Embase in Ovid (searched February 2017, Appendix 3);

- ClinicalTrials.gov (clinicaltrials.gov/, searched February 2017, Appendix 4);

- EU Clinical Trials Register (clinicaltrialsregister.eu/ctr-search/ search, search February 2017, Appendix 4);

- Stroke Trials Registry (strokecenter.org/trials/, searched February 2017, Appendix 4);

- ISRCTN Registry (isrctn.com/; searched February 2017, Appendix 4) (previously Current Controlled Trials (www.controlledtrials.com, searched September 2015); and

- WHO International Clinical Trials Registry Platform (who.int/ ictrp/en/, searched February 2017, Appendix 4).

\section{Searching other resources}

In an effort to identify further published, unpublished and ongoing trials, we screened the reference lists of all relevant trials.

For previous versions of this review, we had:

- contacted the following companies that market LMWHs or heparinoids: Alfa Wasserman (parnaparin and dermatan sulphate), Kabi (dalteparin), Knoll (reviparin), Leo (tinzaparin), Mediolanum (dermatan sulphate), Novo (tinzaparin), Organon (danaparoid), Rhone-Poulenc Rorer (enoxaparin), Sandoz (Sandoz LMWH), and Sanofi Winthrop (nadroparin and CY222); and

- consulted a comprehensive guide to pharmaceutical development in the stroke field (MEDSTRATEGY 1995).

\section{Data collection and analysis}

Two review authors (PS and TL), with the assistance of the Cochrane Stroke Group Information Specialist, performed the searches for this update. The same two review authors independently screened abstracts and titles, and excluded irrelevant studies. We retrieved and independently assessed the full articles of the remaining studies based on the inclusion and exclusion criteria. We resolved disagreements by discussion.

\section{Selection of studies}

Two review authors (PS and CC for the original review; PS and SS for second update; PS and TL for this update) independently selected trials to be included in the review. We resolved disagreements by discussion. Two review authors also assessed the methodological quality of each trial separately.

\section{Data extraction and management}

The two review authors (PS and TL) independently extracted and cross-checked the data. We extracted data such as the number of people with each outcome event, by allocated treatment group, irrespective of compliance, and whether or not the person was subsequently deemed ineligible or otherwise excluded from treatment or follow-up. This approach was applied to allow for an intention-to-treat (ITT) analysis. We sought data on whether or not $\mathrm{CT}$ or MR scanning was performed prior to randomisation. If any of the above data items were not available in the publications, we sought further information by correspondence with the trial authors. We checked to see whether there was evidence to suggest that previously excluded studies should be included and whether ongoing or studies awaiting assessment could be included, but further information was not available for any of these studies.

\section{Assessment of risk of bias in included studies}

For previous versions of this review, the authors did not use a scoring system to assess quality but only assessed risk of bias of included studies. In the previous version, the table of included studies gave details of the randomisation method, blinding, whether an ITT analysis was possible from the published data, and the number of people lost to follow-up. The only dimension of risk of bias that we graded was allocation concealment. However, for this update, we scored the key elements of risk of bias for each included study according to current Cochrane guidelines (Higgins 2011) and generated a risk of bias summary table.

\section{Measures of treatment effect}

Trials of each type of anticoagulant, (LMWHs or heparinoids) were compared to UFH to assess whether there was any difference between these classes of anticoagulants. We reported relative effects as odds ratios (OR, the ratio of the odds of an unfavourable outcome among people treated with either LMWHs or heparinoids versus UFH). We calculated the OR using the Peto fixed-effect method with its $95 \%$ confidence interval $(\mathrm{Cl})$.

\section{Unit of analysis issues}

All the studies included in this review were trials in which all the participants were randomised and followed up for a fixed and predefined period. All analyses were by ITT where possible.

\section{Dealing with missing data}

We contacted original investigators to ask for missing data whenever possible. When this was not possible, we calculated best- and worst-case scenarios: the best-case scenario would mean participants with missing data were alive and the worst-case scenario would mean participants with missing data were dead.

\section{Assessment of heterogeneity}

We tested heterogeneity between study results with the $\mathrm{I}^{2}$ statistic which measures the percentage of the variability in effect estimates 
attributable to heterogeneity (rather than sampling error). We considered a value greater than $50 \%$ as substantial heterogeneity.

\section{Assessment of reporting biases}

We produced funnel plots for two outcomes, death from all causes during treatment period and death from all causes during followup period, to assess the presence of publication bias.

\section{Data synthesis}

We used Review Manager 5 for analysis (RevMan 2014). Trials of each type of anticoagulant, namely LMWHs or heparinoids were compared to UFH to assess whether there was any difference between these classes of anticoagulants. We also assessed the effects of different doses of LMWHs or heparinoids against UFH (5000 IU 12-hourly), applying a test for trend, with due allowance for the fact that such indirect comparisons are prone to bias.

\section{Subgroup analysis and investigation of heterogeneity}

We performed subgroup analysis of the type of anticoagulant agent used (either LMWHs or heparinoids versus UFH) and the dose of anticoagulant used.

\section{Sensitivity analysis}

We carried out sensitivity analyses to determine how sensitive results are to reasonable changes in the assumptions that are made. Furthermore, the potential impact of missing data on the findings of the review was addressed in the Results section (risk of bias, attrition bias). We did not perform a sensitivity analysis based on the frequency of CT or MR scanning at baseline as all studies scanned $100 \%$ of patients before entry.

\section{RE S U L T S}

\section{Description of studies}

\section{Results of the search}

See the PRISMA flow diagram (Figure 1). After the removal of redundant records and previously included trials, we screened a total of 2620 records of titles and abstracts. We selected 17 apparently new trials and, of these, we obtained the full text reports for 10. We then excluded all of these studies after review, leaving no new trials for inclusion. Hence, from the last update, the number of included studies remained the same at nine trials. However, there was a sub-analysis of the PREVAIL 2007 trial which was published in 2009 that contained some additional relevant outcome data that was subsequently included in this updated review. 
Figure 1. PRISMA flow diagram
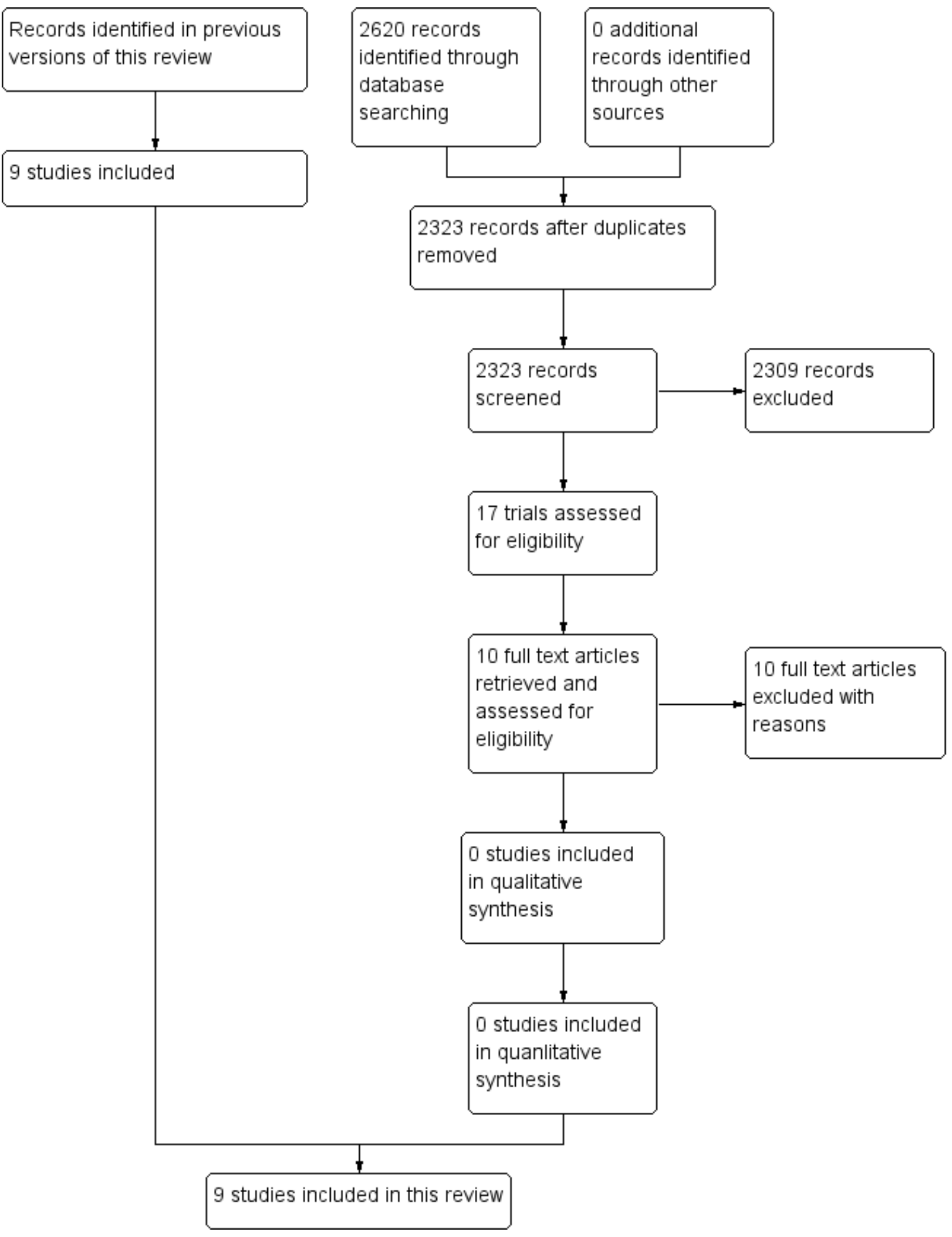


\section{Included studies}

We included nine trials with a total number of 3137 participants (Dumas 1994; Hageluken 1992; Hillbom 1998; PREVAIL 2007; PROTECT 2006; Stiekema 1988; TRACE 2004; Turpie 1992; Wong 2000). Three of the trials have not yet been published in full (Hageluken 1992; Stiekema 1988; Wong 2000). The Characteristics of included studies table provides details of the included trials.

Most participants were enrolled within 72 hours of the stroke, except in two studies which recruited participants less than 24 hours after stroke onset (PROTECT 2006; TRACE 2004). The age of participants in the included trials ranged from 21 years to 91 years with a mean of 68 years. Most trials recruited slightly more males than females. Four trials compared danaparoid (a heparinoid) with unfractionated heparin (UFH) (Dumas 1994; Hageluken 1992; Stiekema 1988; Turpie 1992) and five compared low-molecular-weight heparin (LMWH) with UFH (Hillbom 1998; PREVAIL 2007; PROTECT 2006; TRACE 2004; Wong 2000). All trials administered treatment by the subcutaneous route, although in one trial, treatment began with a single intravenous loading dose of danaparoid (Stiekema 1988).

All the trials reported deaths, either during the treatment or followup periods. The scheduled period of treatment ranged from 6 days to 16 days. Duration of follow-up for all the trials was three months except for two trials, which followed up for 14 days (Stiekema 1988) and 28 days (Wong 2000). All the trials routinely performed computed tomography (CT) scanning in all participants before randomisation to exclude primary intracerebral haemorrhage as a cause of the stroke.

Attempts to contact the authors of a completed trial to gain additional information have been unsuccessful, so we were only able to include the outcome data on CT-confirmed haemorrhage from Wong 2000.

\section{Excluded studies}

We excluded 16 studies in this updated review. We had excluded eight trials from the previous review. In total, we excluded 24 studies for a variety of reasons. The Characteristics of excluded studies table provides summary details.

We excluded one study, comparing enoxaparin with UFH in 38 participants with stroke, because we had sought outcome data on the stroke subset of participants but these data were not provided (EMSG 1996). We excluded another two studies, comparing enoxaparin with UFH, because the stroke participants were not analysed separately and we were concerned that the participants in these two reports overlapped (Harenberg 1999; HESIM 1990). We also excluded studies where the target participants were not acute ischaemic stroke (Assadian 2008; NCT01763606; EXCLAIM 2010; Nikc Evic 2006).

We excluded a large number of studies because the intervention did not include unfractionated heparin (Dunatov 2008; EUROTOAST 1996; Geng 2004; MAGELLAN 2013; Mikulik 2006; Necioglu Orken 2009; Trencev 2008; Xing 2006) or LMWH (Trouillas 2008). One study was confounded because aspirin was part of its comparator (IRCT201109067495N1), and we excluded another study because the two treatment arms were confounded by the co-administration of different warfarin regimens (Feiz 2016). We excluded one trial because the treatment arms were confounded by differing background treatments (Heparinas 2013). One trial (Szirmai 1986) proved on review to have no control group, and we excluded another trial because no data were included in the report (McCarthy 1993).

Two trials published in China were only available as abstracts (Tan 2002; Wang 2012). We attempted to contact relevant authors as well as seek help from colleagues from China to obtain the full text articles but to no avail. A trial of CY 216 compared with UFH was stopped prematurely but remains unpublished and unavailable despite multiple contacts with the author (Moulin 1994). There are two apparently ongoing trials, but we have been unable to contact the authors to gain further information: one of enoxaparin versus UFH (Aventis 2002), and one of LMWH plus warfarin versus UFH plus warfarin (Young 2001).

While there are a large number of excluded studies, they all had small sample sizes, most were confounded in various ways and the inclusion of these studies would not be likely to reduce the random error or degree of bias in the estimates we have derived.

\section{Risk of bias in included studies}

Please refer to Figure 2 and Figure 3 for graphical representation of the risk of bias across all the nine studies. None of the included studies was assessed at low risk of bias in all categories, as each had some threats to validity. We considered some of the studies to have an unclear risk of bias due to the lack of details provided from the paper published. Overall, we judged there to be a moderate risk of bias, chiefly because of inadequate information about allocation concealment and risk of attrition bias. 
Figure 2. Risk of bias graph: review authors' judgements about each risk of bias item presented as percentages across all included studies

Random sequence generation (selection bias)

Allocation concealment (selection bias)

Blinding of participants and personnel (performance bias)

Blinding of outcome assessment (detection bias)

Incomplete outcome data (attrition bias)

Selective reporting (reporting bias)

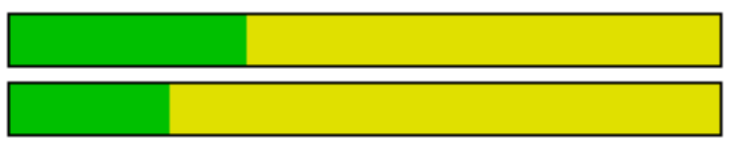

L

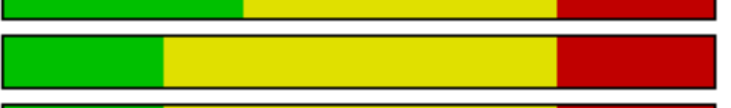

L
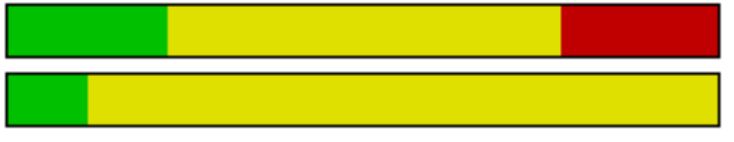

\begin{tabular}{|lllll}
\hline 1 & & 1 & & \\
\hline $0 \%$ & $25 \%$ & $50 \%$ & $75 \%$ & $100 \%$
\end{tabular}

Low risk of bias

Unclear risk of bias

High risk of bias 
Figure 3. Risk of bias summary: review authors' judgements about each risk of bias item for each included study.

\begin{tabular}{|c|c|c|c|c|c|c|}
\hline & 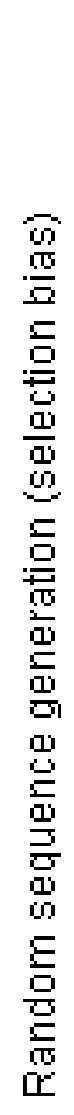 & 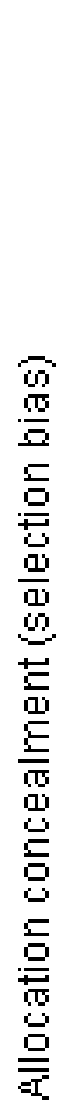 & 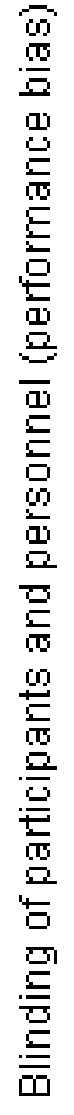 & 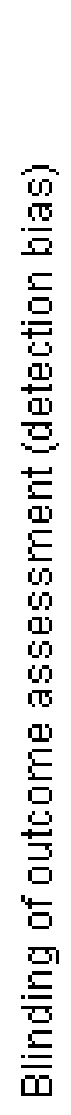 & 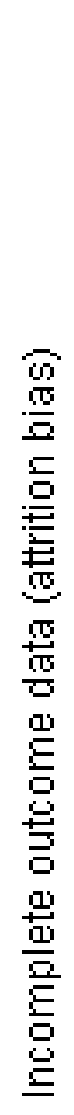 & 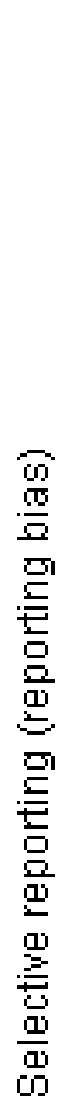 \\
\hline Dumas 1994 & $?$ & $?$ & $?$ & $?$ & $?$ & $?$ \\
\hline Hageluken 1992 & $?$ & ? & $?$ & $?$ & $?$ & $?$ \\
\hline Hillbom 1998 & + & $?$ & & $?$ & + & $?$ \\
\hline PREVAIL 2007 & + & + & & $?$ & $?$ & + \\
\hline PROTECT 2006 & + & + & & & & $?$ \\
\hline Stiekema 1988 & $?$ & $?$ & ? & & & $?$ \\
\hline TRACE 2004 & $?$ & $?$ & & & $?$ & $?$ \\
\hline Turpie 1992 & $?$ & $?$ & + & + & + & $?$ \\
\hline Wong 2000 & $?$ & $?$ & $?$ & $?$ & $?$ & $?$ \\
\hline
\end{tabular}




\section{Allocation}

The method of randomisation was described and considered adequate with low risk of bias in three out of nine of the included trials: Hillbom 1998 used a computer program (ACR/BIOM/STAT) to generate the randomisation sequence and a computer-generated randomisation list was used in PROTECT 2006. Hageluken 1992, Stiekema 1988, TRACE 2004, Turpie 1992 and Wong 2000 reported that the trial was randomised. Dumas 1994 used the sealed envelope method for randomisation. None of these six trials provided details on the method of random sequence generation.

Allocation concealment was adequate in PREVAIL 2007, which used a central randomisation system. Allocation concealment was unclear for six trials: in PROTECT 2006 the report stated only that "treatment allocation was kept strictly confidential and was available only to authorised persons", and in the other five, no details were given (Hageluken 1992; Stiekema 1988; TRACE 2004; Turpie 1992; Wong 2000). In Hageluken 1992 where there was a 3:1 treatment allocation to danaparoid and UFH respectively, there was a relative shortfall in the number of participants allocated to control with 118 allocated to danaparoid UFH and only 27 to control (and not about 40 as would be expected if randomisation had achieved a 3:1 ratio), which may have occurred by chance. However there may be other explanations (such as deliberate or inadvertent subversion of the randomisation process, or unequal proportions of participants excluded after randomisation). Therefore, we performed analyses with this trial included and excluded, to assess its influence on the overall estimates of effect on the different outcomes.

\section{Blinding}

To reduce bias in detecting deep vein thrombosis (DVT), pulmonary embolism (PE), symptomatic intracranial haemorrhage and minor extracranial haemorrhages, adequate blinding is important. Four trials were double-blinded, where treatment allocation was not revealed to outcome assessors, participants and physicians (Dumas 1994; Hillbom 1998; PROTECT 2006; Turpie 1992). Hageluken 1992, Stiekema 1988, and Wong 2000 reported their assessors were single blinded. PREVAIL 2007 and TRACE 2004 did not use any form of blinding and were assessed at high risk of performance and detection bias.

\section{Incomplete outcome data}

Hillbom 1998 and Turpie 1992 stated explicitly that there were no losses to follow-up. PREVAIL 2007 and PROTECT 2006 published trial flow charts, which detailed the degree of losses to follow-up that was sufficient to be a significant source of attrition bias in both trials. The numbers of participants lost to follow-up was not stated in five trials (Dumas 1994; Hageluken 1992; Stiekema 1988; TRACE 2004; Wong 2000).

\section{Selective reporting}

Clinical trial registration details or study protocols were available for only one study (PREVAIL 2007). The primary publication for PREVAIL 2007 did not include numbers of participants who were dead or dependent at follow-up (a secondary paper in 2009 reported mean modified Rankin Scale: PREVAIL 2007). Data on recurrent strokes during the treatment period (up to 14 days) were reported in a subanalysis of PREVAIL 2007 published in 2009. Since these were secondary outcomes for the trial, we considered PREVAIL 2007 at low risk of reporting bias.

For the remainder of the included studies, it was unclear whether any of the older studies were free from reporting bias, largely because study protocols were not available. It is of note that only two provided information on functional outcomes: one on neurological deterioration within 10 days (Wong 2000); and the other on the Barthel index, a measure of functional independence (TRACE 2004). Neither PREVAIL 2007 nor TRACE 2004 provided numerical data. Given the overall quality of the older study reports, and their lack of detail on exactly what data were collected, one cannot rule out a degree of selective reporting of outcomes (in that era, internationally agreed reporting standards for clinical trials had not been published).

\section{Other potential sources of bias}

We sought evidence of publication bias but the number of studies was small (hence limiting the value of this analysis), and the funnel plots did not provide strong evidence of publication bias (Figure 4; Figure 5). 
Figure 4. Funnel plot of comparison: 1 LMWH/heparinoid versus standard UFH in acute ischaemic stroke, outcome: death from all causes during treatment period

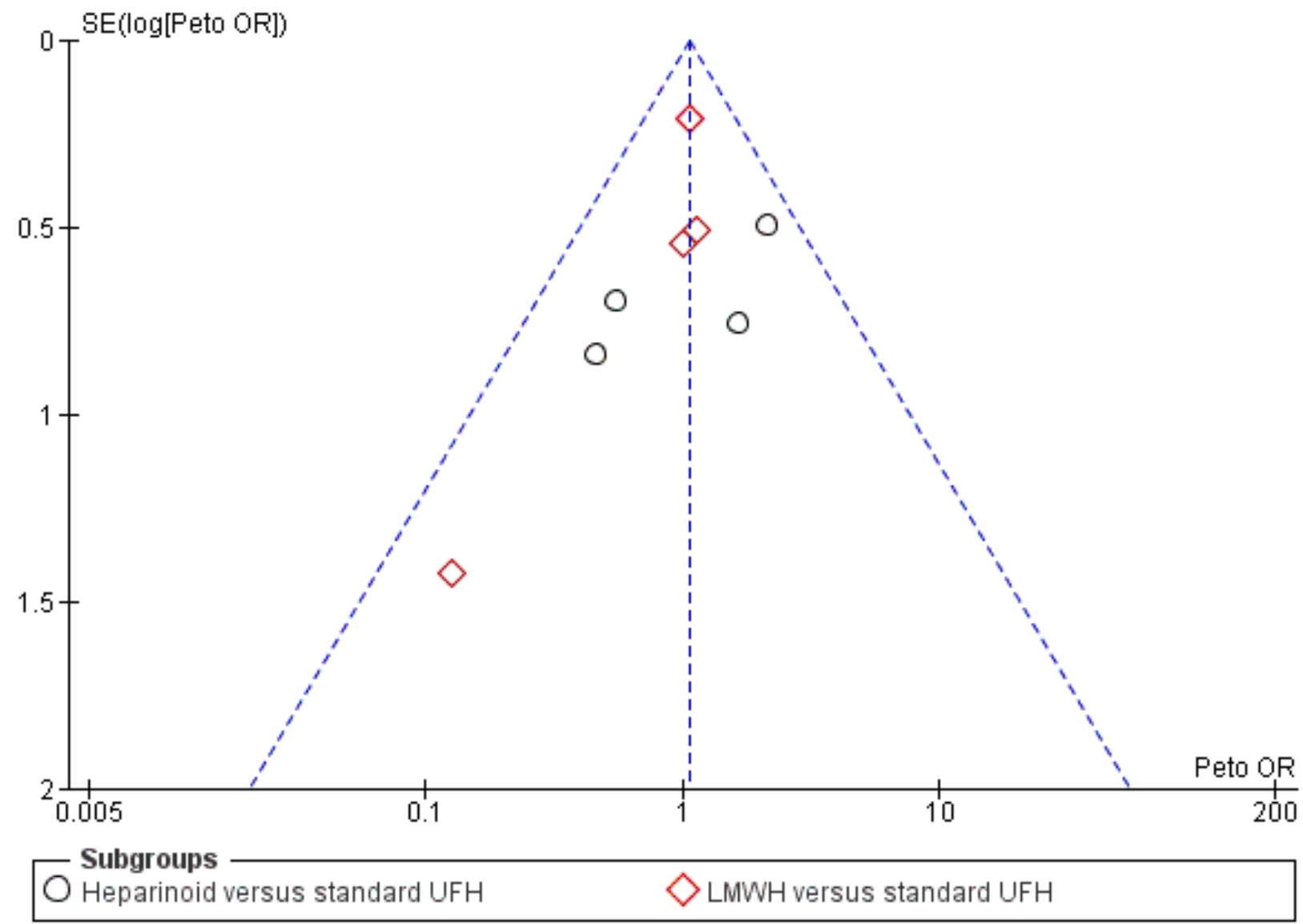


Figure 5. Funnel plot of comparison: $1 \mathrm{LMWH} /$ heparinoid versus standard UFH in acute ischaemic stroke, outcome: death from all causes during follow-up

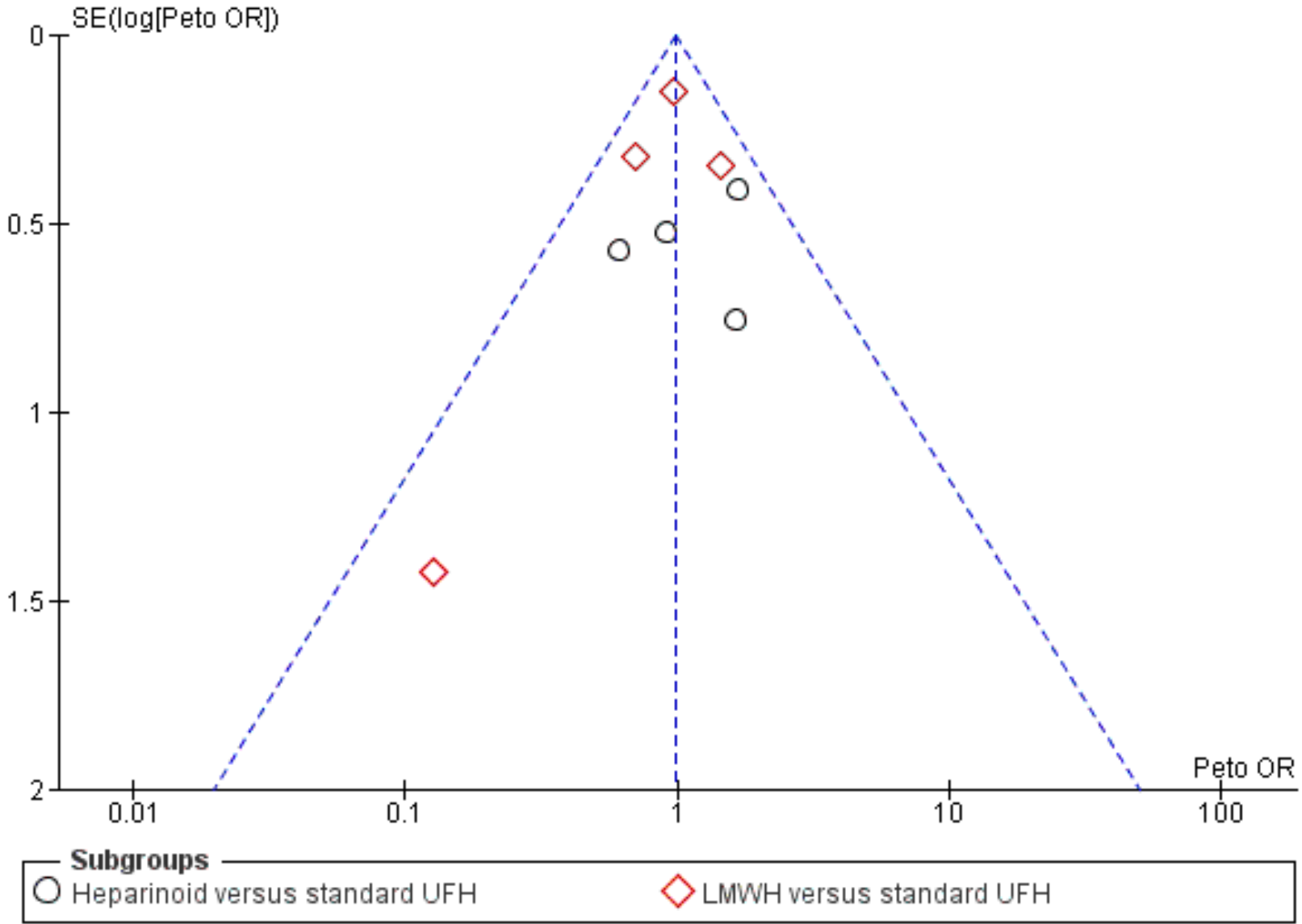

\section{Effects of interventions}

See: Summary of findings for the main comparison Lowmolecular-weight heparins or heparinoids compared with unfractionated heparin for acute ischaemic stroke

\section{Outcome analysis 1.1: Dead or dependent at the end of follow-} up

None of the trials reported this outcome in a form that enabled us to include them for this analysis.

\section{Outcome analysis 1.2: Death from all causes during treatment period}

During the anticoagulation period with LMWH, heparinoids, or UFH, an increased risk of death due to intracranial haemorrhage would only be apparent if most participants had autopsies or CT brain scan shortly before death. However, this was generally not the case, so reliable attribution of any deaths during the treatment period to intracranial haemorrhages was not possible. Intracranial haemorrhage carries an early case fatality of $50 \%$ or more, so analysis of deaths from all causes during the treatment period would be more sensitive to an excess of deaths related to intracranial haemorrhage than an analysis of all deaths during the whole of follow-up. Death data were available from eight trials (Dumas 1994; Hageluken 1992; Hillbom 1998; PREVAIL 2007; PROTECT 2006; Stiekema 1988; TRACE 2004; Turpie 1992) with 3102 participants (98.8\% of the total participants included in the review). Overall, there was no significant difference in all cause death during the scheduled treatment period between $\mathrm{LMWH}$ or heparinoids and UFH (OR $1.06,95 \% \mathrm{Cl} 0.78$ to 1.46 , low quality evidence; Analysis 1.2). There was no significant heterogeneity $\left(I^{2}=0 \%\right)$.

\section{Outcome analysis 1.3: Death from all causes during follow-up}

Data from eight trials with 3102 participants were available for this outcome. There was no significant difference between LMWH or heparinoid and UFH (OR $0.98,95 \% \mathrm{CI} 0.79$ to 1.23 , low quality evidence; Analysis 1.3). There was no significant heterogeneity $\left(\mathrm{I}^{2}=0 \%\right)$ among the interventions. The confidence interval was compatible with substantial harm (an extra 2 deaths per 100 people treated) and substantial benefit ( 2 fewer deaths per 100 people treated). Any - even a small - excess of deaths associated with danaparoid or LMWH could clearly offset any benefits from reductions in DVT and PE.

\section{Outcome analysis 1.4: Vascular death during follow-up}

Significant and important beneficial or adverse effects on specific causes of death may be missed if crude analysis was undertaken only on deaths from all causes. Important effects of treatment on vascular deaths may be obscured if a large proportion of deaths were due to non-vascular causes (and hence very unlikely to be influenced by anticoagulant agents). Data on cause-specific 
mortality in each treatment group with 1038 participants (33\% of the total participants in the review) were available for this outcome. There was no significant difference in vascular death between those allocated danaparoid or LMWH versus those allocated UFH (OR $1.15,95 \% \mathrm{Cl} 0.72$ to $1.85, \mathrm{I}^{2}=0 \%$, low quality evidence; Analysis 1.4).

\section{Outcome analysis 1.5: DVT during treatment period}

Seven trials that included a total of 2585 participants $(82.4 \%$ of the total number of participants included in the review) reported data on DVT detected systematically. Methods of detecting DVT were variable. Four trials used $\mathrm{I}^{125}$ fibrinogen scanning, two mostly used contrast venography, and one used Doppler ultrasound detecting only proximal leg DVT. Nevertheless, some participants either did not have the appropriate investigation or had an inadequate assessment of DVT. For instance, in Hillbom 199830 participants allocated enoxaparin and 34 allocated UFH did not have venography or had an inadequate examination; in Dumas 1994 four participants allocated UFH did not have valid I25 fibrinogen scans or venograms; in Hageluken 199216 participants allocated to danaparoid and eight participants allocated to UFH did not have valid DVT assessments; and in PREVAIL 2007218 participants allocated enoxaparin and 209 allocated UFH had no or an inadequate assessment of DVT. These participants were retained in their original treatment groups for the main analysis, and we assumed that none had a DVT, except for PREVAIL 2007, where there were many excluded participants and so DVT was analysed in the per-protocol efficacy population.

The proportion of participants not undergoing venography was quite high in a number of studies. A modified worst-case scenario analysis was performed with the assumption that the excluded participants in the LMWH or heparinoid arm had a DVT rate that was equal to the highest rate in any arm in any included trial $31 \%$ in the Turpie 1992 UFH arm) and those excluded in the UFH arm had a DVT rate equal to the lowest rate in any arm (7\% in the PROTECT 2006 LMWH arm). This method has been applied in other Cochrane Reviews (Macleod 2005; Sandercock 2003a).

As a whole, allocation to LMWH or heparinoid was associated with a significant reduction in DVT (OR $0.55,95 \% \mathrm{Cl} 0.44$ to $0.70, \mathrm{P}<$ $0.00001, I^{2}=0 \%$, low quality evidence; Analysis 1.5$)$. However, the result was no longer statistically significant in the modified worstcase scenario analysis (OR $0.86,95 \% \mathrm{Cl} 0.70$ to 1.06 ). Both the heparinoid (OR $0.52,95 \% \mathrm{Cl} 0.31$ to $0.86, \mathrm{P}=0.01)$ and the LMWH (OR $0.56,95 \% \mathrm{Cl} 0.44$ to $0.73, \mathrm{P}<0.00001$ ) regimens were associated with lower incidence of DVT compared with UFH.

\section{Outcome analysis 1.6: PE during follow-up}

Six trials, involving 1250 participants (39.8\% of the total number of participants), presented data on symptomatic PE. However, not all surviving participants had pulmonary ventilation scans because confirmation of PE was not sought systematically. Furthermore, not all participants who died had autopsies, which could lead to bias in the results. In addition, there were too few participants with PE to generate substantial evidence on whether or not the observed trend in favour of $\mathrm{LMWH}$ or heparinoid was significant or happened merely by chance (OR $0.57,95 \% \mathrm{Cl} 0.23$ to $1.41, \mathrm{I}^{2}=0 \%$; Analysis 1.6). In the published report of Turpie 1992, no PEs were recorded, but unpublished data suggested a high possibility in one participant (who died but did not have an autopsy) in the UFH group. We excluded PREVAIL 2007 from our analyses because data were only available for the treatment period and not the scheduled follow- up period (PE occurring during the treatment in 1/666 enoxaparin versus $6 / 669$ UFH participants, absolute risk difference $-0.7 \%, 95 \%$ $\mathrm{Cl}-1.5$ to 0$)$.

\section{Outcome analysis 1.7: Any intracranial haemorrhage/ haemorrhagic transformation of the cerebral infarct during treatment period}

Irresepctive of clinical deterioration, ideally an unbiased assessment of the effect of treatment on the occurrence of intracranial haemorrhage or haemorrhagic transformation of the infarct (HTI) would come from studies in which $\mathrm{CT}$ or MR scanning was performed systematically in all surviving participants at the beginning and end of the scheduled treatment period. However, the overall risk of intracranial haemorrhage may have been underestimated because it did not include those participants who may have died from an intracranial haemorrhage before a second scan could be performed and did not have an autopsy. The compromise of this scenario and the least biased and most fair assessment would be of the effect of treatment on the intracranial haemorrhage event or HTI detected by routine repeat CT scanning performed at the end of the scheduled treatment period in all survivors and by autopsy in all those who died during the treatment period (Sandercock 1993). However, none of the included studies undertook this as a pre-specified analysis.

All trials also reported intracranial haemorrhage associated with clinical deterioration (symptomatic HTI) but this analysis could lead to bias, particularly if the trial was not double-blind. In addition, the definition of deterioration varied between trials. 'Any HTI' was relatively uncommon ( $2.4 \%$ in all groups combined) and 'symptomatic HTI' was even more rare $(0.9 \%$ in all groups combined). We may have underestimated the risk of any HTI somewhat because in Hillbom 1998 approximately 10\% (20/212) of participants did not have a repeat CT scan and we assumed these participants did not have a haemorrhage. For this comparison (9 trials, 3137 participants) there was no significant difference in any HTI between LMWH or heparinoid and UFH (OR $0.75,95 \% \mathrm{Cl} 0.46$ to $1.23, P=0.25, I^{2}=0 \%$, low quality evidence; Analysis 1.7 ).

\section{Outcome analysis 1.8: Symptomatic intracranial haemorrhage/haemorrhagic transformation of the infarct during treatment period}

Data were available for eight trials (3102 participants). Overall, there was no significant difference in symptomatic HTI for LMWH or heparinoid versus UFH (OR $0.73,95 \% \mathrm{Cl} 0.35$ to $1.54, \mathrm{I}^{2}$ $=0 \%$; Analysis 1.8). However, these analyses were based on very small numbers of events so the confidence intervals were very wide, implying that the available data were inadequate to provide reliable evidence on any possible excess risk of intracranial haemorrhage associated with LMWH or heparinoid compared with UFH.

\section{Outcome analysis 1.9: Extracranial haemorrhage during treatment period}

Seven trials (3012 participants; 96\% of included participants) reported data on extracranial haemorrhage during the treatment period. Only 14 major extracranial haemorrhages occurred $(0.5 \%$ of all participants); this very low absolute risk of serious bleeding is probably related to the fact that participants considered to be at high risk of bleeding were excluded from the trials. LMWH or danaparoid were associated with a substantially higher risk of 
major extracranial bleeding than UFH (OR $3.79,95 \% \mathrm{Cl} 1.30$ to 11.06 , $1^{2}=0 \%$; Analysis 1.9).

Information on minor haemorrhages is probably less reliable because it was less systematically reported and definitions varied; for example, some trials reported minor bruising at the injection site whilst others did not. Minor extracranial haemorrhages were common (6.5\% of all participants) and were mainly related to skin haematomas (formed by blood clots, and giving rise to a swelling under the skin) at the injection sites, mild haematemesis (vomiting of blood) in participants with nasogastric tubes, or mild haematuria (blood in urine) in participants with urinary catheters. There was no difference in minor bleeds in those participants allocated to LMWH or danaparoid compared with UFH (OR $0.91,95 \% \mathrm{Cl} 0.67$ to $1.24, \mathrm{I}^{2}$ $=0 \%$ ).

\section{Outcome analysis 1.10: Effect of recurrent ischaemic stroke or recurrent stroke of unknown pathological type during treatment period}

Two trials, TRACE 2004 and PREVAIL 2007, with 1839 participants, reported this outcome, which occurred in $8 / 923$ participants allocated to LMWH or heparinoid versus 4/916 participants allocated to UFH; there was no evidence of a difference in this outcome between the two groups (OR 1.94, 95\% Cl 0.61 to $6.11, \mathrm{I}^{2}=$ $27 \%$, low quality evidence; Analysis 1.10).

\section{Indirect comparisons of different doses of heparinoid with standard heparin}

Indirect comparisons suggested that 350 anti-Xa units daily of danaparoid may be less effective at preventing DVT than 5000 IU of UFH twice daily (although the data were limited; Analysis 1.11). Although there were trends towards greater benefit in terms of DVT prevention with larger doses of danaparoid and with twice daily compared with once daily administration, these were not significant and were based on very few data. The data on the safety of different doses of danaparoid with regard to haemorrhages were also extremely limited although there was the suggestion that higher doses or twice daily administration may produce more haemorrhages than UFH (Analysis 1.12).

\section{Sensitivity analyses}

There was no evidence of a significant difference in any outcome between danaparoid and LMWH. The inclusion or exclusion of three trials as a result of their potentially inadequate allocation concealment did not materially affect the overall conclusions (Hageluken 1992; TRACE 2004; Wong 2000).

\section{Publication bias}

We performed a funnel plot analysis to determine whether an important number of small negative trials were missed as a form of publication bias. We generated funnel plots for two outcomes: death from all causes during the treatment period (Figure 4), and death from all causes during follow-up period (Figure 5). These figures showed a degree of asymmetry, indicating possible publication bias, with under-reporting of studies favouring UFH. However, it should be interpreted with caution due to the small number of studies, making the power of the test too low to distinguish chance from real asymmetry (Higgins 2011).

\section{DISCUSSION}

It is not yet clear whether routine use of any anticoagulant treatment at all in acute stroke is beneficial (Sandercock 2015), and so it is perhaps premature to start comparing different anticoagulant regimens. In contrast, aspirin has been shown to be effective in improving neurological outcomes and preventing pulmonary embolism (PE) following ischaemic stroke and carries little risk of major haemorrhage (Sandercock 2014).

\section{Summary of main results}

\section{Overall benefit of low-molecular-weight heparin (LMWH) or heparinoids versus unfractionated heparin (UFH) in acute ischaemic stroke}

None of the included trials reported information on the primary outcome for this Cochrane Review update. Overall the included trials were at moderate risk of bias, and the quality of evidence for all outcomes assessed was low according to GRADE criteria. The analyses, which included only limited data on major clinical outcomes, suggested that, while LMWH or heparinoids may yield greater protection against deep vein thrombosis (DVT) than UFH, such benefits might be offset by an excess of intracranial haemorrhages and major extracranial haemorrhages, but the data on these potential risks in this update were inadequate. The numbers of deaths, intracranial haemorrhages, and major extracranial haemorrhages were small, and so the confidence intervals were wide and hence could not rule out significant harm from LMWH or heparinoids.

For example, in PREVAIL 2007, although the risk of venous thromboembolism (VTE) (symptomatic plus asymptomatic) was significantly lower among participants given LMWH, the study could not exclude a $69 \%$ increase in the risk of death up to day 14 and a $134 \%$ increase in the risk of intracranial haemorrhage with $\mathrm{LMWH}$. This was because the event rates for these major clinical outcomes were low: PE and intracerebral haemorrhage occurred in $1 \%$ of participants respectively. It was challenging to conduct a trial large enough to assess the balance risk and benefit of the intervention with such low event rates.

\section{Prevention of DVT and PE in acute ischaemic stroke by LMWH or heparinoids versus UFH}

As a whole, allocation to LMWH or heparinoid was associated with a significant reduction in DVT but the result was no longer statistically significant in the modified worst-case scenario analysis. Many DVTs detected in stroke patients are clinically silent, and there is debate about the extent to which reductions in asymptomatic DVT correlate with reductions in clinically significant episodes of VTE (Lowe 2003). There were too few people with PE among the included trials to generate substantial evidence on whether or not the observed trend in favour of LMWH or heparinoid was merely by chance.

\section{Risk of intra- and extracranial haemorrhage in acute ischaemic stroke with LMWH or heparinoids versus UFH}

Although there was no significant difference in intracranial haemorrhage between LMWH or heparinoid and UFH during treatment periods, in participants allocated to LMWH or heparinoid versus UFH, there was a statistically significant increase in major extracranial haemorrhages. However, there were only 14 major 
extracranial haemorrhages ( $0.5 \%$ of all participants). This very low absolute risk of serious bleeding was probably related to the fact that participants considered to be at high risk of bleeding were excluded from the trials. Information on minor haemorrhages should be interpreted cautiously because these events were systematically reported less frequently and definitions varied; for example, some trials reported minor bruising at the injection site but others did not. There was no difference in minor bleeds among participants allocated to LMWH or danaparoid compared with UFH.

\section{Overall completeness and applicability of evidence}

Most included trials were conducted more than 10 years ago, which may raise concerns about whether these results are still relevant for current clinical practice. The management of people with acute ischaemic stroke in the past two decades has changed, especially where acute stroke units have been established that provide better general care, early rehydration and active mobilisation which may reduce VTE frequency. On the other hand, greater use of intravenous thrombolysis may increase the haemorrhagic risks of anticoagulation. However, these changes in background clinical care may be expected to alter the absolute risks of various outcomes, but not greatly alter the estimates of relative effect of anticoagulation. It is unclear whether these data remain relevant in current clinical practice.

\section{Quality of the evidence}

Five of nine included trials did not specify methods of random sequence generation, and eight did not specify how allocation concealment was achieved, leading to assessment of unclear risk of selection bias. Most included trials did not provide sufficient information to enable assessment of selective reporting, hence risk of reporting bias was assessed as unclear (Figure 3). Overall, for each of the outcomes reported in our 'Summary of findings' table, the quality of evidence was graded as low. Furthermore, the largest trial, PREVAIL 2007 ( $N=1762)$, was unblinded, which may have led to performance bias that could potentially affect review findings. The funnel plot analysis included too few studies to provide reliable evidence of, or reliably to exclude, publication bias.

This review does not reliably answer the question it set out to address: whether heparinoids or LMWHs are more effective, yet as safe as UFH to prevent neurological disability and VTE in people with acute ischaemic stroke. To provide guidance on which categories of people with ischaemic stroke may benefit from heparinoids or LMWHs, and more accurate and precise estimates of the risks of death and haemorrhage, much larger randomised controlled trials are required that compare danaparoid (or LMWHs) with UFH and with control in many thousands of participants. It is unlikely that any trial of this size could ever be performed.

\section{Potential biases in the review process}

Completeness of the searches: we are confident that the Cochrane Stroke Group Trials Register is an efficient and reliable way of identifying registered and ongoing trials relevant to this review. The extensive searches performed for the 2008 review and in 2015 for this update did not identify any major large-scale studies that were underway at the time of searching. The Cochrane Stroke Group Trials Register was searched again in July 2016 before this update was submitted. However, given the large number of apparently randomised stroke trials reported in scant detail in hard-to-access literature in China, it is possible that some may have been eligible for inclusion. The reports we have been able to obtain from China (Tan 2002; Wang 2012; Wong 2000) were only available as abstracts and none clearly met our inclusion criteria. At least one trial was closed but never reported data (Moulin 1994), and another three are thought to be ongoing trials but no details were available (Aventis 2002; Heparinas 2013; Young 2001). The changes to the protocol between the previous version and this update were minor and could not have introduced bias, since no data were available for our primary outcome.

\section{Agreements and disagreements with other studies or reviews}

A non-Cochrane review of LMWH versus UFH in people with ischaemic stroke supported the use of LMWH, due to the benefit of reducing venous thromboembolism (Shorr 2008). The study reported that there were no statistically significant increases in haemorrhage or death compared with UFH. However, a more recent and comprehensive review of heparin for DVT prophylaxis in medical patients found that in hospitalised medical patients (including those with stroke), heparin prophylaxis had no significant effect on mortality, may have reduced PE in medical patients and all patients combined, and led to more bleeding and major bleeding events, thus resulting in little or no net benefit (Lederle 2011).

\section{What is new in this update?}

For this update, the main searches were performed up to February 2017. We identified no new studies that met review inclusion criteria. We identified a report of a sub-analysis of the PREVAIL 2007 trial published in 2009 that contained limited additional outcome data which were subsequently included in this updated review. However, the overall results and conclusions remained the same as 2008 (Sandercock 2008). In previous versions of this review, outcomes were not divided into primary or secondary outcomes. In this updated review, the primary outcome was identified as the proportion dead or dependent in activities in daily living. We added more detailed assessment of risk of bias, funnel plots to assess for publication bias and a summary of findings table.

\section{AUTHORS' CONCLUSIONS}

\section{Implications for practice}

For clinicians who, despite the lack of evidence of overall benefit from routine anticoagulants in people with acute ischaemic stroke, still wish to use some form of anticoagulant regimen in selected people with acute ischaemic stroke:

- the criteria to identify those few people that might benefit from the unfractionated heparin (UFH), low-molecular-weight heparin $(\mathrm{LMWH})$ or heparinoid regimens tested in these trials have not been defined;

- LMWH and heparinoids appear to be more effective at preventing deep venous thrombosis (DVT) - and possibly also pulmonary embolism (PE) - than UFH. However, their safety, compared with UFH, has not reliably been established in people with stroke.

\section{Implications for research}

It may well be that other antithrombotic agents, such as aspirin, will prove to be the antithrombotic agent with the most 
favourable balance of risk and benefit for use in people with acute ischaemic stroke. Further very large-scale trials may be worthwhile comparing:

- aspirin alone with aspirin plus low-dose LMWH (or heparinoid) in individuals at particularly high risk of DVT and PE; and

- a more aggressive LMWH (or heparinoid) regimen with UFH and with aspirin only in certain categories of people, for example those with a cardiac source of emboli. These trials should measure disability and recurrent stroke as well as venous thromboembolism and major haemorrhages.

Given the lack of evidence for the routine use of any anticoagulant regimen in acute ischaemic stroke and the evidence in favour of using aspirin, further trials comparing only heparinoids or LMWH with UFH would be hard to justify.

\section{ACKNOWLEDGEMENTS}

We express appreciation to Hazel Fraser, Brenda Thomas, and Joshua Cheyne of the Cochrane Stroke Group for providing regular updates of newly identified trials and for help with trial searching. We also acknowledge Dr Carl Counsell and Dr Mei Chiun Tseng who contributed greatly for the previous version and updates of the review.

\section{Ongoing trials}

Any clinician who knows of additional trials that we have omitted please write to Professor Peter Sandercock. 


\section{RE F E R E N C E S}

\section{References to studies included in this review}

Dumas 1994 \{published and unpublished data\}

* Dumas R, Woitinas F, Kutnowski M, Nikolic I, Berberich R, Abedinpour F, et al. A multi-centre double blind randomized study to compare the safety and efficacy of once-daily ORG 10172 and twice-daily low-dose heparin in preventing deepvein thrombosis in patients with acute ischaemic stroke. Age and Ageing 1994;23(6):512-6.

Hageluken C, Egberts J, Stiekema J. A multi-centre, assessorblind, randomised, safety study of Org 10172, administered subcutaneously twice daily, for the prophylaxis of deep vein thrombosis in patients with a non-haemorrhagic stroke of recent onset (protocol 87038). Organon International B.V. (Internal report SDGRR No. 3165), Oss, The Netherlands 1992.

\section{Hageluken 1992 \{unpublished data only\}}

Hageluken C, Egberts J. A multi-centre, assessor-blind, randomised pilot study of three different doses of Org 10172 (375, 750 and 1250U), administered subcutaneously once daily, compared with low dose heparin, administered subcutaneously twice daily, in the prophylaxis of deep vein thrombosis (DVT) in patients with a non-haemorrhagic stroke of recent onset (protocol 85144). Organon International B.V. (Internal report SDGRR No. 3158). Oss, the Netherlands 1992.

\section{Hillbom 1998 \{published and unpublished data\}}

Hillbom M, Erila T, Flosbach C, Sotaniemi K, Tatlisumak T, Sarna S, et al. Enoxaparin, a low-molecular-weight heparin (LWMH) may be superior to standard heparin in the prevention of deep-vein thrombosis (DVT) in stroke patients. European Journal of Neurology 1998;5(Suppl 3):S110.

Hillbom M, Erila T, Flosbach CW, Sotaniemi K, Sarna S, Kaste M. Enoxaparin, a low molecular weight heparin, is superior to heparin in the prevention of deep vein thrombosis in patients with acute atherosclerotic stroke. Proceedings of the 17th Congress of the International Society on Thrombosis and Haemostasis; 1999 August 14-21; Washington, DC, USA. 1999.

Hillbom M, Erila T, Sotaniemi K, Tatlisumak T, Sarna S, Kaste M. Comparison of the efficacy and safety of the low-molecularweight heparin enoxaparin with unfractionated heparin in the prevention of deep vein thrombosis in patients with acute ischaemic stroke. Blood 1999;94(Suppl 1):183a.

* Hillbom M, Erila T, Sotaniemi K, Tatlisumak T, Sarna S, Kaste M. Enoxaparin vs heparin for prevention of deep-vein thrombosis in acute ischaemic stroke: a randomized, doubleblind study. Acta Neurologica Scandinavica 2002;106(2):84-92.

\section{PREVAIL 2007 \{published data only\}}

Kase CS, Albers GW, Bladin C, Fieschi C, Gabbai AA, O'Riordan W, et al. Neurological outcomes in patients with ischemic stroke receiving enoxaparin or heparin for venous thromboembolism prophylaxis: subanalysis of the Prevention of VTE after Acute Ischemic Stroke with LMWH (PREVAIL) study. Stroke 2009;40(11):3532-40. [DOI: 10.1161/STROKEAHA.109.555003]
* Sherman DG, Albers GW, Bladin C, Fieschi C, Gabbai AA, Kase CS, et al. The efficacy and safety of enoxaparin versus unfractionated heparin for the prevention of venous thromboembolism after acute ischaemic stroke (PREVAIL Study): an open-label randomised comparison. Lancet 2007;369(9570):1347-55.

\section{PROTECT 2006 \{published data only\}}

Diener H-C, Ringelstein EB, von Kummer R, Landgraf H, Koppenhagen K, Harenberg J, et al. Prophylaxis of thrombotic and embolic events in acute ischemic stroke with the lowmolecular-weight heparin certoparin. Results of the PROTECT Trial. Stroke 2006;37(1):139-44.

\section{Stiekema 1988 \{published and unpublished data\}}

Hossman V, Loettgen J, Auel H, Bewermeyer H, Heiss WD. Prophylaxis of deep vein thrombosis in acute stroke. A prospective, randomised double-blind study. Haemostasis 1986;16(Suppl 5):54.

* Stiekema JCJ, Egberts JFM, Voerman J. An open, randomised, pilot multi-centre study of Org 10172 versus heparin administered for the purpose of deep vein thrombosis prophylaxis in patients with a non-haemorrhagic stroke of recent onset. Organon International B.V. (Internal report SDGRR No. 2310). Oss, The Netherlands 1988.

\section{TRACE 2004 \{published data only\}}

Woessner R, Grauer M, Bianchi O, Mueller M, Moersdorf S, Berlit $\mathrm{P}$, et al. Treatment with anticoagulants in cerebral events (TRACE). Thrombosis and Haemostasis 2004;91(4):690-3.

\section{Turpie 1992 \{published and unpublished data\}}

Magnani HN, Egberts JFM. A preliminary report of a multicentre, assessor-blind, randomised, comparative safety and efficacy study of Org 10172 versus low dose heparin, administered subcutaneously twice daily for the prophylaxis of deep vein thrombosis in patients with acute thrombotic stroke (protocol 004-010). Organon International B.V (Internal report SDGRR No.3172). Oss, the Netherlands 1992.

Turpie AGG. Orgaran in the prevention of deep vein thrombosis in stroke patients. Haemostasis 1992;22(2):92-8.

Turpie AGG, Levine MN, Powers PJ, Ginsberg JG, Jay RM, Klimek M, et al. A double blind randomized trial of Org 10172 low molecular weight heparinoid versus unfractionated heparin in the prevention of deep venous thrombosis in patients with thrombotic stroke. Thrombosis and Haemostasis 1991;65:753.

* Turpie AGG, Levine MN, Powers PJ, Ginsberg JG, Jay RM, Klimek M, et al. A low-molecular-weight heparinoid compared with unfractionated heparin in the prevention of deep vein thrombosis in patients with acute ischemic stroke. Annals of Internal Medicine 1992;117(5):353-7.

Wong 2000 \{published and unpublished data\}

Wong WJ, Lo YK, Hu HH. Comparison of subcutaneous low-molecular heparin with intravenous standard heparin 
in progressive ischaemic stroke. Journal of Stroke and Cerebrovascular Diseases 2000;9(Suppl 1):183-4.

\section{References to studies excluded from this review}

Assadian 2008 \{published data only\}

Assadian A, Knobl P, Hubl W, Senekowitsch C, Klingler A, Pfaffelmeyer N, et al. Safety and efficacy of intravenous enoxaparin for carotid endarterectomy: a prospective randomized pilot trial. Journal of Vascular Surgery 2008;47(3):537-42.

\section{Dunatov 2008 \{published and unpublished data\}}

Dunatov S, Antoncic I, Strenja-Linic I, Tuskan-Mohar L. Low molecular weight heparin (LMWH) as an adjunct to thrombolysis for acute stroke. International Journal of Stroke 2008;3 (Suppl 1):238.

\section{EMSG 1996 \{published data only\}}

Bergmann JF, Neuhart E. A multicenter randomized doubleblind study of enoxaparin compared with unfractionated heparin in the prevention of venous thromboembolic disease in elderly in-patients bedridden for an acute medical illness. Thrombosis and Haemostasis 1996;76(4):529-34.

EUROTOAST 1996 \{published data only (unpublished sought but not used)\}

Egberts JFM, Sommer W. Multicentre, randomised, assessorblind, dose-comparative study of Org 10172 (Orgaran) in the treatment of acute ischaemic stroke. Personal communication by letter 1996.

\section{EXCLAIM 2010 \{published data only\}}

Hull RD, Schellong SM, Tapson VF, Monreal M, Samama MM, Nicol P, et al. Extended-duration venous thromboembolism prophylaxis in acutely ill medical patients with recently reduced mobility: a randomized trial. Annals of Internal Medicine 2010;153(1):8-18. [DOI: 10.7326/0003-4819-153-1-201007060-00004]

\section{Feiz 2016 \{published data only\}}

Feiz F, Sedghi R, Salehi A, Hatam N, Bahmei J, BorhaniHaghigi A. Study of the efficacy, safety and tolerability of low-molecular weight heparin vs unfractionated heparin as bridging therapy for patients with embolic stroke due to atrial fibrillation. Journal of Vascular and Interventional Neurology 2016;9(1):35-41.

\section{Geng 2004 \{published data only\}}

Geng S, Wang Y, Liu P. Intravenous drip of urokinase combined with low molecular weight heparin in the treatment of acute cerebral infarction. Practical Journal of Medicine and Pharmacy 2004;21(7):604-6.

\section{Harenberg 1999 \{published data only\}}

Harenberg J, Schomaker U, Floshbach CW. Enoxaparin is superior to unfractionated heparin in the prevention of thromboembolic events in medical patients at increased thromboembolic risk. Blood 1999;94(Suppl 10):399a.
Heparinas 2013 \{published data only\}

Dluha J, Sivak S, Kurca E, Dusenka R, Kalmarova K, TurcanovaKoprusakova M, et al. The safety and efficacy of heparin and nadroparin compared to placebo in acute ischemic stroke pilot study. Biomedical Papers 2016;160(4):543-8.

NCT01862978. Safety and efficacy of heparin and nadroparin in the acute phase of ischaemic stroke (Heparinas). clinicaltrials.gov/ct2/show/NCT01862978 (first received 20 May 2013).

\section{HESIM 1990 \{published data only\}}

Harenberg J, Kallenbach B, Martin U, Dempfle CE, Zimmermann R, Kubler W, et al. Randomized controlled study of heparin and low molecular weight heparin for prevention of deep-vein thrombosis in medical patients. Thrombosis Research 1990;59(3):639-50.

Harenberg J, Roebruck P, Stehle G, Habscheid W, Biegholdt M, Heene DL, et al. Heparin study in internal medicine (HESIM): design and preliminary results. Thrombosis Research 1992;68(1):33-43.

\section{IRCT201109067495N1 \{published and unpublished data\}}

IRCT201109067495N1. Clinical trial on enoxaparine and aspirin effects on mobility problems of non-hemorrhagic stroke patients. en.search.irct.ir/view/7105 (first received 10 December 2011).

\section{MAGELLAN 2013 \{published data only\}}

Cohen AT, Spiro TE, Büller HR, Haskell L, Hu D, Hull R, MAGELLAN Investigators. Rivaroxaban for thromboprophylaxis in acutely ill medical patients. New England Journal of Medicine 2013;368(6):513-52. [DOI: 10.1056/NEJMoa1111096]

\section{McCarthy 1993 \{unpublished data only\}}

McCarthy S, McWalter R, Durkin CJ, Hallawi AH. Org 10172 for the prophylaxis of deep venous thrombosis in the legs. A protocol to establish the efficacy and safety of once or twice daily subcutaneous Org 10172 injections vs placebo in 3 groups of 60 non-haemorrhagic stroke victims. Unpublished protocol.

\section{Mikulik 2006 \{published data only\}}

Mikulik R, Dufek M, Goldemund D, Reif M. A pilot study on systemic thrombolysis followed by low molecular weight heparin in ischemic stroke. European Journal of Neurology 2006;13(10):1106-11.

\section{Moulin 1994 \{unpublished data only\}}

Crepin-Leblond T, Moulin T, Ziegler F, Bataillard M, Chopard L, Chavot $D$, et al. A randomised trial of heparin therapy in acute ischemic stroke: first results. Cerebrovascular Diseases 1994;4:259.

NCT01763606 \{published and unpublished data\}

NCT01763606. Enoxaparin versus aspirin in patients with cancer and stroke. clinicaltrials.gov/ct2/show/NCT01763606 (first received 20 December 2012). 
Necioglu Orken 2009 \{published data only\}

Necioglu Orken D, Kenangil G, Ozkurt H, Guner C, Gundogdu L, Basak M, et al. Prevention of deep venous thrombosis and pulmonary embolism in patients with acute intracerebral hemorrhage. The Neurologist 2009;15(6):329-31.

Nikc Evic 2006 \{published data only\}

Nikc Evic LD, Savic MB, Plavsic AT, Hrkovic MK. Applying of LMWH (clexane) and results of early rehabilitation in patients after ischemic stroke. International Journal of Stroke 2006;1(Suppl 1):153.

\section{Szirmai 1986 \{unpublished data only\}}

Szirmai I, Fendler K, Kollár L, Romhányi M. Clinical experience with heparinoid sodium pentosan polysulphate (SP54) in treatment of cerebral ischaemia. Folia Haematologia (Leipzig) 1986;113(1-2):278-88.

\section{Tan 2002 \{published data only\}}

Tan A. The application research on the treatment of acute ischemic stroke by using low molecular weight heparins and small dose of heparins. Journal of Medical Theory and Practice 2002;15(11):1246-7.

\section{Trencev 2008 \{published data only\}}

Trencev R, Stojanov M, Petrovska-Cvetkovska D, Georgievska A, Baneva N, Radulovic-Bekarovska S. Low-molecular-weight heparin vs aspirin in treatment of cardioembolic stroke. International Journal of Stroke 2008; Vol. 3, issue Suppl 1:315-6.

\section{Trouillas 2008 \{published data only\}}

Trouillas P, Derex L, Philippeau F, Cakmak S, Nighoghossian N, Zeng L. RT-PA and heparin in the LYON RT-PA protocol: beneficial effect of intravenous heparin on outcome and intracerebral bleeding at specific times of initiation. Cerebravascular Diseases 2008;25(Suppl 2):42-3.

\section{Wang 2012 \{published data only\}}

Wang ZY, Wang LC, Chen C, Gen JY, Gao YS. A controlled study on the treatment of acute progressive cerebral infarction by continuous anticoagulation with small doses of heparin Chinese Critical Care Medicine 2012;24(5):290-3.

\section{Xing 2006 \{published data only\}}

Xing ZW, Shi YD. Clinical observation of combined clopidogrel and low molecular heparin in progressive ischemic stroke. Chinese Journal of Contemporary Neurology and Neurosurgery 2006;6(1):44-6.

\section{References to ongoing studies}

\section{Aventis 2002 \{unpublished data only\}}

Aventis Pharma. An open-label, randomised, parallel-group, multi-centre study to evaluate the efficacy and safety of enoxaparin versus unfractionated heparin in the prevention of venous thromboembolism in patients following acute ischaemic stroke. Unpublished.
Young 2001 \{unpublished data only\}

Young WD, Smythe LG. Low-molecular-weight heparin (enoxaparin) in anticoagulation transition to oral warfarin in ischaemic cerebral vascular accident (CVA) or transient ischaemic attack (TIA) patients. ASHP Midyear Clinical Meeting. 2001; Vol. 36:496E.

\section{Additional references}

\section{Amin 2013}

Amin AN, Lin J, Thompson S, Wiederkehr D. Rate of deepvein thrombosis and pulmonary embolism during the care continuum in patients with acute ischemic stroke in the United States. BMC Neurology 2013;13:17. [DOI: 10.1186/1471-2377-13-17]

\section{Bath 2000}

Bath P, Iddenden R, Bath F. Low-molecular weight heparins and heparinoids in acute ischemic stroke. Stroke 2000;31(7):1770-8.

\section{Caplan 2009}

Caplan LR. Caplan's stroke: a clinical approach. Basic Pathology, Anatomy, and Pathophysiology of Stroke. 4th Edition. Philadelphia: Saunders Elsevier, 2009:22.

\section{Cella 1986}

Cella G, Scattolo N, Luzzato G, Stevanato F, Vio C, Girolami A. Effects on platelets and on the clotting system of four glycosaminoglycans extracted from hog mucosa and one extracted from aortic intima of the calf. Journal of Medicine 1986;17(5-6):331-46.

\section{Choay 1989}

Choay J. Structure and activity of heparin and its fragments: an overview. Seminars in Thrombosis and Hemostasis 1989;15(4):359-64

\section{Chung 2016}

Chung JW, Kim BJ, Han MK, Ko Y, Lee S, Kang K, et al. Impact of guidelines on clinical practice: intravenous heparin use for acute ischemic stroke. Stroke 2016;47(6):1577-83. [DOI: 10.1161] STROKEAHA.116.012639]

\section{CLOTS3 2015}

Dennis M, Sandercock P, Graham C, Forbes J, Clots Trials Collaboration. The Clots in Legs Or sTockings after Stroke (CLOTS) 3 trial: a randomised controlled trial to determine whether or not intermittent pneumatic compression reduces the risk of post-stroke deep vein thrombosis and to estimate its cost-effectiveness. Health Technology Assessment 2015;19(76):1-90. [DOI: 10.3310/hta19760]

\section{Cruickshank 1991}

Cruickshank MK, Levine MN, Hirsh J, Roberts R, Siguenza M. A standard heparin nomogram for the management of heparin therapy. Archives of Internal Medicine 1991;151(2):333-7.

\section{Garcia 2012}

Garcia DA, Baglin TP, Weitz JI, Samama MM, American College of Chest Physicians. Parenteral anticoagulants: Antithrombotic 
Therapy and Prevention of Thrombosis, 9th ed: American College of Chest Physicians Evidence-Based Clinical Practice Guidelines. Chest 2012;141:e24S-43S.

\section{Gordon 1990}

Gordon DL, Linhardt R, Adams HP. Low-molecular-weight heparins and heparinoids and their use in acute or progressing ischemic stroke. Clinical Neuropharmacology 1990;13(6):522-43.

\section{Gubitz 2004}

Gubitz G, Sandercock P, Counsell C. Anticoagulants for acute ischaemic stroke. Cochrane Database of Systematic Reviews 2004, Issue 3. [DOI: 10.1002/14651858.CD000024.pub2]

\section{Higgins 2011}

Higgins JPT, Green S (editors). Cochrane Handbook for Systematic Reviews of Interventions Version 5.1.0 [updated March 2011]. The Cochrane Collaboration, 2011. www.cochranehandbook.org.

\section{Holbrook 2012}

Holbrook A, Schulman S, Witt DM, Vandvik PO, Fish J, Kovacs MJ. Evidence-based management of anticoagulant therapy: antithrombotic therapy and prevention of thrombosis, 9th ed: American College of Chest Physicians Evidence-Based Clinical Practice Guidelines. Chest 2012;141:52s.

\section{IST 1997}

International Stroke Trial Collaborative Group. The International Stroke Trial (IST): a randomised trial of aspirin, subcutaneous heparin, both, or neither among 19435 patients with acute ischaemic stroke. Lancet 1997;349(9065):1569-81.

\section{Lederle 2011}

Lederle FA, Zylla D, MacDonald R, Wilt TJ. Venous thromboembolism prophylaxis in hospitalized medical patients and those with stroke: a background review for an American College of Physicians Clinical Practice Guideline. Annals of Internal Medicine 2011;155(9):602-15.

\section{Lozano 2012}

Lozano R, Naghavi M, Foreman K, Lim S, Shibuya K, Aboyans V, et al. Global and regional mortality from 235 causes of death for 20 age groups in 1990 and 2010: a systematic analysis for the Global Burden of Disease Study 2010. Lancet 2012;380(9859):2095-128. [DOI: 10.1016/ S0140-6736(12)61728-0]

\section{Meuleman 1992}

Meuleman DG. Orgaran (Org 10172): Its pharmacological profile in experimental models. Haemostasis 1992;22(2):58-65.

\section{Odgaard-Jensen 2011}

Odgaard-Jensen J, Vist Gunn E, Timmer A, Kunz R, Akl EA, Schnemann $\mathrm{H}$, et al. Randomisation to protect against selection bias in healthcare trials. Cochrane Database of Systematic Reviews 2011, Issue 4. [DOI: 10.1002/14651858.MR000012.pub3]

\section{RevMan 2014 [Computer program]}

Copenhagen: The Nordic Cochrane Centre, The Cochrane Collaboration. Review Manager (RevMan). Version 5.3.
Copenhagen: The Nordic Cochrane Centre, The Cochrane Collaboration, 2014.

\section{Sandercock 1993}

Sandercock PAG, van den Belt A, Lindley R, Slattery J. Antithrombotic therapy in acute stroke: an overview of the randomised trials. Journal of Neurology, Neurosurgery \& Psychiatry 1993;56(1):17-25.

\section{Sandercock 2014}

Sandercock P, Counsell C, Tseng MC, Cecconi E. Oral antiplatelet therapy for acute ischaemic stroke. Cochrane Database of Systematic Reviews 2014, Issue 3. [DOI: 10.1002/14651858.CD000029.pub3]

\section{Sandercock 2015}

Sandercock P, Counsell C, Kane EJ. Anticoagulants for acute ischaemic stroke. Cochrane Database of Systematic Reviews 2015, Issue 3. [DOI: 10.1002/14651858.CD000024]

\section{Shorr 2008}

Shorr AF, Jackson WL, Sherner JH, Moores LK. Differences between low-molecular weight and unfractionated heparin for venous thromboembolism prevention following ischemic stroke: a meta-analysis. Chest 2008;133(1):149-55.

\section{TOAST 1998}

Publications Committee for the Trial of Org 10172 in Acute Stroke Treatment (TOAST) Investigators. Low molecular weight heparinoid ORG 10172 (Danaparoid) and outcome after acute ischemic stroke. JAMA 1998;279(16):1265-72.

\section{Warlow 2008}

Warlow C, Dennis M, Van Gijn J, Sandercock P, Bamford J, Rothwell P, Rinkel G, Sudlow C, Wardlaw J. Stroke: A practical Guide to Management .. 3. Oxford: Blackwell Science 2008, 2008.

\section{Weitz 1997}

Weitz JI. Low-molecular-weight heparins. New England Journal of Medicine 1997;337(10):688.

\section{References to other published versions of this review Counsell 2001}

Counsell C, Sandercock P. Low-molecular-weight heparins or heparinoids versus standard unfractionated heparin for acute ischaemic stroke. Cochrane Database of Systematic Reviews 2001, Issue 4. [DOI: 10.1002/14651858.CD000119]

\section{Sandercock 2005}

Sandercock P, Counsell C, Stobbs SL. Low-molecular-weight heparins or heparinoids versus standard unfractionated heparin for acute ischaemic stroke. Cochrane Database of Systematic Reviews 2005, Issue 2. [DOI: 10.1002/14651858.CD000119.pub2]

\section{Sandercock 2008}

Sandercock PAG, Counsell C, Tseng M-C. Low-molecular-weight heparins or heparinoids versus standard unfractionated heparin for acute ischaemic stroke. Cochrane Database of Systematic Reviews 2008, Issue 3. [DOI: 10.1002/14651858.CD000119.pub3] 


\section{CHARACTERISTICS OF STUDIES}

Characteristics of included studies [ordered by study ID]

\section{Dumas 1994}

\begin{tabular}{|c|c|c|}
\hline Methods & \multicolumn{2}{|c|}{$\begin{array}{l}\mathrm{R}=\text { sequentially numbered identical containers } \\
\text { Double blind } \\
\text { ITT } \\
\text { Number lost to FU: not stated }\end{array}$} \\
\hline Participants & \multicolumn{2}{|c|}{$\begin{array}{l}\text { Europe } \\
76 \text { men, } 103 \text { women, mean age } 72 \text { years } \\
100 \% \text { CT before entry } \\
\text { Ischaemic stroke with leg paresis } \\
\text { Less than } 72 \text { hours since stroke onset }\end{array}$} \\
\hline Interventions & \multicolumn{2}{|c|}{$\begin{array}{l}\text { Rx: Org } 10172 \text { sc ( } 1250 \text { anti-Xa units } 24 \text {-hourly) } \\
\text { Control: heparin sc ( } 5000 \text { IU } 12 \text {-hourly) } \\
\text { Duration: } 9 \text { to } 13 \text { days }\end{array}$} \\
\hline Outcomes & \multicolumn{2}{|c|}{$\begin{array}{l}\text { Death + cause of death } \\
\text { DVT (systematic I I } 25 \text { scan with venography) } \\
\text { PE (symptomatic) } \\
\text { Intracranial haemorrhage (systematic CT) } \\
\text { Extracranial haemorrhage }\end{array}$} \\
\hline Notes & \multicolumn{2}{|c|}{$\begin{array}{l}\text { Ex: BP greater than } 200 / 120 \text {, bleeding risk } \\
\text { FU: } 3 \text { months }\end{array}$} \\
\hline \multicolumn{3}{|l|}{ Risk of bias } \\
\hline Bias & Authors' judgement & Support for judgement \\
\hline $\begin{array}{l}\text { Random sequence genera- } \\
\text { tion (selection bias) }\end{array}$ & Unclear risk & Method of sequence generation not stated \\
\hline $\begin{array}{l}\text { Allocation concealment } \\
\text { (selection bias) }\end{array}$ & Unclear risk & Sealed envelope, but no details provided \\
\hline $\begin{array}{l}\text { Blinding of participants } \\
\text { and personnel (perfor- } \\
\text { mance bias) } \\
\text { All outcomes }\end{array}$ & Unclear risk & $\begin{array}{l}\text { Treatment and control arms both involved } 2 \mathrm{x} \text { daily injections. Manuscript } \\
\text { states "patients, physicians and hospital staff were unaware of treatment allo- } \\
\text { cation" }\end{array}$ \\
\hline $\begin{array}{l}\text { Blinding of outcome as- } \\
\text { sessment (detection bias) } \\
\text { All outcomes }\end{array}$ & Unclear risk & $\begin{array}{l}\text { Treatment and control arms both involved } 2 \mathrm{x} \text { daily injections. Manuscript } \\
\text { states "patients, physicians and hospital staff were unaware of treatment allo- } \\
\text { cation" }\end{array}$ \\
\hline $\begin{array}{l}\text { Incomplete outcome data } \\
\text { (attrition bias) } \\
\text { All outcomes }\end{array}$ & Unclear risk & Number lost to follow-up not stated \\
\hline $\begin{array}{l}\text { Selective reporting (re- } \\
\text { porting bias) }\end{array}$ & Unclear risk & $\begin{array}{l}\text { Study protocol not available, study report does not give full details of data col- } \\
\text { lected during follow-up }\end{array}$ \\
\hline
\end{tabular}


Hageluken 1992

\begin{tabular}{|c|c|c|}
\hline Methods & \multicolumn{2}{|c|}{$\begin{array}{l}\mathrm{R}=\text { sequentially numbered containers } \\
\text { Single blind (assessor) } \\
\text { ITT } \\
\text { Number lost to FU: not stated }\end{array}$} \\
\hline Participants & \multicolumn{2}{|c|}{$\begin{array}{l}\text { Europe } \\
79 \text { men, } 66 \text { women, mean age } 69 \text { years } \\
100 \% \text { CT before entry } \\
\text { Ischaemic stroke with leg paresis } \\
\text { Less than } 72 \text { hours since stroke onset }\end{array}$} \\
\hline Interventions & \multicolumn{2}{|c|}{$\begin{array}{l}\text { Rx: Org } 10172 \text { sc ( } 375 \text { anti-Xa units } 24 \text {-hourly); Org } 10172 \text { sc ( } 750 \text { anti-Xa units } 24 \text {-hourly); Org } 10172 \text { sc } \\
\text { (1250 anti-Xa units } 24 \text {-hourly) } \\
\text { Control: heparin sc (5000 IU 12-hourly) } \\
\text { Duration: } 9 \text { to } 11 \text { days }\end{array}$} \\
\hline Outcomes & \multicolumn{2}{|c|}{$\begin{array}{l}\text { Death + cause of death } \\
\text { DVT (systematic I I } 25 \text { scan with venography) } \\
\text { PE (symptomatic) } \\
\text { Intracranial haemorrhage (systematic CT) } \\
\text { Extracranial haemorrhage }\end{array}$} \\
\hline Notes & \multicolumn{2}{|c|}{$\begin{array}{l}\text { Ex: BP greater than } 200 / 120 \text {, bleeding risk } \\
\text { FU: } 3 \text { months }\end{array}$} \\
\hline \multicolumn{3}{|l|}{ Risk of bias } \\
\hline Bias & Authors' judgement & Support for judgement \\
\hline $\begin{array}{l}\text { Random sequence genera- } \\
\text { tion (selection bias) }\end{array}$ & Unclear risk & Method of randomisation not reported \\
\hline $\begin{array}{l}\text { Allocation concealment } \\
\text { (selection bias) }\end{array}$ & Unclear risk & Allocation concealment not reported \\
\hline $\begin{array}{l}\text { Blinding of participants } \\
\text { and personnel (perfor- } \\
\text { mance bias) } \\
\text { All outcomes }\end{array}$ & Unclear risk & No details provided \\
\hline $\begin{array}{l}\text { Blinding of outcome as- } \\
\text { sessment (detection bias) } \\
\text { All outcomes }\end{array}$ & Unclear risk & No details provided \\
\hline $\begin{array}{l}\text { Incomplete outcome data } \\
\text { (attrition bias) } \\
\text { All outcomes }\end{array}$ & Unclear risk & No details provided \\
\hline $\begin{array}{l}\text { Selective reporting (re- } \\
\text { porting bias) }\end{array}$ & Unclear risk & $\begin{array}{l}\text { Study protocol not available, study report does not give full details of data col- } \\
\text { lected during follow-up }\end{array}$ \\
\hline
\end{tabular}

Hillbom 1998

$\begin{array}{ll}\text { Methods } & \begin{array}{l}\mathrm{R}=\text { sequentially numbered containers } \\ \text { Double blind }\end{array}\end{array}$


Hillbom 1998 (Continued)

ITT

No loss to FU

\begin{tabular}{|c|c|}
\hline Participants & $\begin{array}{l}\text { Finland } \\
127 \text { men, } 85 \text { women, mean age } 69 \text { years } \\
100 \% \text { CT before entry } \\
\text { Ischaemic stroke with leg paresis for more than } 24 \text { hours since stroke onset }\end{array}$ \\
\hline Interventions & $\begin{array}{l}\text { Rx: enoxaparin ( } 40 \mathrm{mg} \text { once daily) } \\
\text { Control: heparin SC (5000 IU 8-hourly) } \\
\text { Duration: } 10 \pm 2 \text { days or discharge if sooner }\end{array}$ \\
\hline Outcomes & $\begin{array}{l}\text { Death } \\
\text { DVT (systematic venography) } \\
\text { PE (symptomatic) } \\
\text { Extracranial haemorrhage } \\
\text { Intracranial haemorrhage (systematic CT) }\end{array}$ \\
\hline Notes & $\begin{array}{l}\text { Ex: specified by protocol - includes bleeding risk; GCS <9; pre-existing DVT } \\
\text { FU: } 3 \text { months } \\
\text { Sponsoring pharmaceutical company stopped before planned sample size of } 400 \text { people recruited, be- } \\
\text { cause of very slow recruitment rate }\end{array}$ \\
\hline
\end{tabular}

\section{Risk of bias}

\begin{tabular}{|c|c|c|}
\hline Bias & Authors' judgement & Support for judgement \\
\hline $\begin{array}{l}\text { Random sequence genera- } \\
\text { tion (selection bias) }\end{array}$ & Low risk & $\begin{array}{l}\text { Randomisation schedule had a block size of } 4 \text { and was generated by computer } \\
\text { programme AC/BIOM/STAT }\end{array}$ \\
\hline $\begin{array}{l}\text { Allocation concealment } \\
\text { (selection bias) }\end{array}$ & Unclear risk & $\begin{array}{l}\text { Method for the participating doctor to obtain the treatment allocation not } \\
\text { stated }\end{array}$ \\
\hline $\begin{array}{l}\text { Blinding of participants } \\
\text { and personnel (perfor- } \\
\text { mance bias) } \\
\text { All outcomes }\end{array}$ & Low risk & $\begin{array}{l}\text { Experimental and control treatments supplied in prefilled syringes of identical } \\
\text { appearance }\end{array}$ \\
\hline $\begin{array}{l}\text { Blinding of outcome as- } \\
\text { sessment (detection bias) } \\
\text { All outcomes }\end{array}$ & Unclear risk & Steps to blind assessors not stated \\
\hline $\begin{array}{l}\text { Incomplete outcome data } \\
\text { (attrition bias) } \\
\text { All outcomes }\end{array}$ & Low risk & Manuscript states no patients lost to follow-up \\
\hline $\begin{array}{l}\text { Selective reporting (re- } \\
\text { porting bias) }\end{array}$ & Unclear risk & $\begin{array}{l}\text { Study protocol not available, study report does not give full details of data col- } \\
\text { lected during follow-up }\end{array}$ \\
\hline
\end{tabular}

PREVAIL 2007

Methods $\quad \mathrm{R}=$ blocked and stratified randomisation, telephone to central randomisation system

Study treatment was not blinded

ITT

Follow up: not available for 32 (15 Rx, 17 control) either by withdrawal of consent or loss to FU

Participants International

Low-molecular-weight heparins or heparinoids versus standard unfractionated heparin for acute ischaemic stroke (Review) 
PREVAIL 2007 (Continued)

994 men, 768 women, mean age 66 years

$100 \%$ CT or MRI before entry

Ischaemic stroke and unable to walk unassisted

$<48$ hours since stroke onset

NIHSS score 2 or more

\begin{tabular}{ll}
\hline Interventions & Rx: enoxaparin 40 mg sc once daily \\
& Control: heparin sc (5000 IU 12-hourly) \\
& Duration: 10 days (range 6 to 14) \\
\hline Outcomes & Death \\
& DVT (systematic venography or ultrasound if venography not possible) \\
& PE (symptomatic) \\
& Extracranial haemorrhage \\
& Intracranial haemorrhage (systematic CT) \\
& Modified Rankin Scale \\
\hline Notes & Ex: specified by protocol \\
& FU: 90 days \\
Sponsored by Sanofi-Aventis (Paris, France)
\end{tabular}

\section{Risk of bias}

\begin{tabular}{|c|c|c|}
\hline Bias & Authors' judgement & Support for judgement \\
\hline $\begin{array}{l}\text { Random sequence genera- } \\
\text { tion (selection bias) }\end{array}$ & Low risk & $\begin{array}{l}\text { The sponsor generated the randomisation schedule in permuted blocks of } 4 \text {, } \\
\text { stratified by baseline stroke severity that was implemented centrally by an in- } \\
\text { dependent interactive voice-response system }\end{array}$ \\
\hline $\begin{array}{l}\text { Allocation concealment } \\
\text { (selection bias) }\end{array}$ & Low risk & $\begin{array}{l}\text { The randomisation schedule was implemented centrally by an independent } \\
\text { interactive voice-response system }\end{array}$ \\
\hline $\begin{array}{l}\text { Blinding of participants } \\
\text { and personnel (perfor- } \\
\text { mance bias) } \\
\text { All outcomes }\end{array}$ & High risk & Not blinded \\
\hline $\begin{array}{l}\text { Blinding of outcome as- } \\
\text { sessment (detection bias) } \\
\text { All outcomes }\end{array}$ & Unclear risk & $\begin{array}{l}\text { Not blinded, but all major outcome events were reviewed blind to treatment } \\
\text { allocation by an adjudication committee }\end{array}$ \\
\hline $\begin{array}{l}\text { Incomplete outcome data } \\
\text { (attrition bias) } \\
\text { All outcomes }\end{array}$ & Unclear risk & $\begin{array}{l}\text { Primary outcome data not available for } 32 \text { participants, number with missing } \\
\text { modified Rankin Scale status not stated }\end{array}$ \\
\hline $\begin{array}{l}\text { Selective reporting (re- } \\
\text { porting bias) }\end{array}$ & Low risk & Trial registered NCT00077805, protocol-specified outcomes all reported \\
\hline
\end{tabular}

\section{PROTECT 2006}

\begin{tabular}{ll} 
Methods & R = computer-generated randomisation list \\
& Double-blind \\
& ITT \\
& Losses to follow up: 67 (34 Rx, 33 control) \\
\hline Participants & European Union \\
& 313 men, 232 women, 18 to 85 years, mean age 67 years
\end{tabular}


PROTECT 2006 (Continued)

100\% CT before entry

Ischaemic stroke with leg paresis

Less than 24 hours since stroke onset

NIHSS score 4 to 30

Rx: certoparin sc (3000 U once daily) plus 2 injections of placebo
Control: heparin sc (5000 IU 8-hourly)
Duration: 12 to 16 days

\begin{tabular}{ll}
\hline Outcomes & Death related to DVT \\
& Proximal leg DVT (ultrasound) \\
& PE (symptomatic) \\
& Extracranial haemorrhage \\
& Intracranial haemorrhage (systematic CT) \\
& \\
\hline \multirow{2}{*}{ Ex:es } & FU: 3 months \\
& Sponsored by Novartis (Nürnberg, Germany)
\end{tabular}

\section{Risk of bias}

\begin{tabular}{|c|c|c|}
\hline Bias & Authors' judgement & Support for judgement \\
\hline $\begin{array}{l}\text { Random sequence genera- } \\
\text { tion (selection bias) }\end{array}$ & Low risk & Random sequence generated by computer \\
\hline $\begin{array}{l}\text { Allocation concealment } \\
\text { (selection bias) }\end{array}$ & Low risk & $\begin{array}{l}\text { Manuscript states "Treatment allocation kept strictly confidential and avail- } \\
\text { able only to authorised persons" }\end{array}$ \\
\hline $\begin{array}{l}\text { Blinding of participants } \\
\text { and personnel (perfor- } \\
\text { mance bias) } \\
\text { All outcomes }\end{array}$ & Low risk & Experimental and control treatments identical in appearance \\
\hline $\begin{array}{l}\text { Blinding of outcome as- } \\
\text { sessment (detection bias) } \\
\text { All outcomes }\end{array}$ & Low risk & Experimental and control treatments identical in appearance \\
\hline $\begin{array}{l}\text { Incomplete outcome data } \\
\text { (attrition bias) } \\
\text { All outcomes }\end{array}$ & High risk & $64(10 \%)$ participants lost to follow-up \\
\hline $\begin{array}{l}\text { Selective reporting (re- } \\
\text { porting bias) }\end{array}$ & Unclear risk & $\begin{array}{l}\text { Study protocol not available, study report does not give full details of data col- } \\
\text { lected during follow-up }\end{array}$ \\
\hline
\end{tabular}

Stiekema 1988

\begin{tabular}{ll}
\hline Methods & $\mathrm{R}=$ sequentially numbered containers \\
& Single blind (assessor) \\
& Loss to follow-up not stated \\
\hline Participants & Europe \\
& 43 men, 39 women, 21 to 91 years \\
& $100 \%$ CT before entry \\
& Ischaemic stroke with leg paresis \\
& Less than 72 hours since stroke \\
\hline
\end{tabular}


Stiekema 1988 (Continued)

Interventions
Rx: loading dose 1000 anti-Xa units iv, then Org 10172 sc (1250 anti-Xa units 12-hourly) or Org 10172 sc

(750 anti-Xa units 12-hourly)

Control: heparin sc (5000 IU 12-hourly)

Duration: 10 days

\begin{tabular}{ll}
\hline Outcomes & Death + cause of death \\
& DVT (systematic I ${ }^{125}$ scan with venography) \\
& PE (symptomatic) \\
Intracranial haemorrhage (systematic CT) & Extracranial haemorrhage \\
\hline Notes & Ex: $B P>200 / 120$, bleeding risk \\
& FU: 14 days
\end{tabular}

\section{Risk of bias}

\begin{tabular}{lll}
\hline Bias & Authors' judgement & Support for judgement \\
\hline $\begin{array}{l}\text { Random sequence genera- } \\
\text { tion (selection bias) }\end{array}$ & Unclear risk & Method of randomisation not reported \\
\hline $\begin{array}{l}\text { Allocation concealment } \\
\text { (selection bias) }\end{array}$ & Unclear risk & Method of allocation concealment not stated \\
\hline $\begin{array}{l}\text { Blinding of participants } \\
\text { and personnel (perfor- } \\
\text { mance bias) } \\
\text { All outcomes }\end{array}$ & Unclear risk & $\begin{array}{l}\text { Report to company describes this as an open trial, published abstract states } \\
\text { double blind }\end{array}$ \\
\hline $\begin{array}{l}\text { Blinding of outcome as- } \\
\text { sessment (detection bias) }\end{array}$ & High risk & Not blinded \\
\hline $\begin{array}{l}\text { Incomplete outcome data } \\
\text { (attrition bias) } \\
\text { All outcomes }\end{array}$ & High risk & Loss to follow-up not stated \\
\hline $\begin{array}{l}\text { Selective reporting (re- } \\
\text { porting bias) }\end{array}$ & Unclear risk & $\begin{array}{l}\text { Study protocol not available, study report does not give full details of data col- } \\
\text { lected during follow-up }\end{array}$ \\
\hline
\end{tabular}

\section{TRACE 2004}

\begin{tabular}{|c|c|}
\hline Methods & $\begin{array}{l}\mathrm{R}=\text { not described } \\
\text { Unblinded } \\
\text { ITT } \\
\text { Losses to follow up: not stated }\end{array}$ \\
\hline Participants & $\begin{array}{l}\text { Germany } \\
\text { Caucasian, } 57 \text { men, } 33 \text { women, mean age } 68 \text { years } \\
100 \% \text { CT or MRI before entry } \\
\text { Ischaemic stroke less than } 24 \text { hours since stroke onset }\end{array}$ \\
\hline Interventions & $\begin{array}{l}\text { Rx: enoxaparin } 1 \mathrm{mg} / \mathrm{kg} \text { sc twice daily ( } 100 \text { Anti-Xa units } 12 \text {-hourly) } \\
\text { Control: heparin iv (initial bolus of } 80 \mathrm{IU} / \mathrm{kg} \text {, followed by } 18 \mathrm{IU} / \mathrm{kg} / \mathrm{h} \text { ) } \\
\text { Duration: } 8 \pm 2 \text { days }\end{array}$ \\
\hline
\end{tabular}


TRACE 2004 (Continued)

Outcomes Death

Reduction in microembolic signals compared with baseline on day 2 and 5 (TCD verified)

Cerebral ischaemic events, systemic embolic events, and bleeding complications

Barthel Index

Notes Ex: specified by protocol - includes bleeding risk, severe organic cerebral disease

FU: 3 months

\section{Risk of bias}

\begin{tabular}{lll}
\hline Bias & Authors' judgement & Support for judgement \\
\hline $\begin{array}{l}\text { Random sequence genera- } \\
\text { tion (selection bias) }\end{array}$ & Unclear risk & Not stated \\
\hline $\begin{array}{l}\text { Allocation concealment } \\
\text { (selection bias) }\end{array}$ & Unclear risk & Not stated \\
\hline $\begin{array}{l}\text { Blinding of participants } \\
\text { and personnel (perfor- } \\
\text { mance bias) } \\
\text { All outcomes }\end{array}$ & High risk & Not blinded \\
\hline $\begin{array}{l}\text { Blinding of outcome as- } \\
\text { sessment (detection bias) } \\
\text { All outcomes }\end{array}$ & High risk & Not blinded \\
\hline $\begin{array}{l}\text { Incomplete outcome data } \\
\text { (attrition bias) } \\
\text { All outcomes }\end{array}$ & Unclear risk & Not stated \\
\hline $\begin{array}{l}\text { Selective reporting (re- } \\
\text { porting bias) }\end{array}$ & Unclear risk & $\begin{array}{l}\text { Study protocol not available, study report does not give full details of data col- } \\
\text { lected during follow-up }\end{array}$ \\
\hline
\end{tabular}

\section{Turpie 1992}

\begin{tabular}{ll}
\hline Methods & R = sequentially numbered identical containers \\
Double blind \\
ITT \\
No loss to FU \\
\hline Participants & Canada \\
& 38 men, 49 women, mean age 72 years \\
& $100 \%$ CT before entry \\
& Non-embolic ischaemic stroke with leg paresis \\
& Les than 7 days since stroke onset \\
\hline Interventions & Rx: Org 10172 sc (750 anti-Xa units 12-hourly) \\
Control: heparin sc (5000 IU 12-hourly) \\
Duration: 14 days \\
\hline Death \\
DVT (systematic I 125 scan + plethysmography with venography) \\
PE (symptomatic) \\
Intracranial haemorrhage (systematic CT) \\
\hline
\end{tabular}


Turpie 1992 (Continued)
Notes
Ex: bleeding risk; pre-existing DVT
FU: 3 months

\section{Risk of bias}

\begin{tabular}{|c|c|c|}
\hline Bias & Authors' judgement & Support for judgement \\
\hline $\begin{array}{l}\text { Random sequence genera- } \\
\text { tion (selection bias) }\end{array}$ & Unclear risk & Method of sequence generation not stated \\
\hline $\begin{array}{l}\text { Allocation concealment } \\
\text { (selection bias) }\end{array}$ & Unclear risk & Method for concealment not stated \\
\hline $\begin{array}{l}\text { Blinding of participants } \\
\text { and personnel (perfor- } \\
\text { mance bias) } \\
\text { All outcomes }\end{array}$ & Low risk & $\begin{array}{l}\text { Participamts, trial nurses, and physicians were all unaware of treatment allo- } \\
\text { cation }\end{array}$ \\
\hline $\begin{array}{l}\text { Blinding of outcome as- } \\
\text { sessment (detection bias) } \\
\text { All outcomes }\end{array}$ & Low risk & $\begin{array}{l}\text { Participamts, trial nurses, and physicians were all unaware of treatment allo- } \\
\text { cation }\end{array}$ \\
\hline $\begin{array}{l}\text { Incomplete outcome data } \\
\text { (attrition bias) } \\
\text { All outcomes }\end{array}$ & Low risk & No losses to follow-up \\
\hline $\begin{array}{l}\text { Selective reporting (re- } \\
\text { porting bias) }\end{array}$ & Unclear risk & $\begin{array}{l}\text { Study protocol not available, study report does not give full details of data col- } \\
\text { lected during follow-up }\end{array}$ \\
\hline
\end{tabular}

Wong 2000

\begin{tabular}{ll} 
Methods & $\begin{array}{l}\mathrm{R}=\text { not stated } \\
\text { Single blind (CT scans only) } \\
\text { Loss to follow-up not stated }\end{array}$ \\
\hline Participants & Taiwan \\
& 35 participants \\
& 2 groups had similar baseline characteristics \\
& $100 \%$ CT before entry \\
Increase in severity or number of neurological symptoms less than 48 hours since stroke onset & GCS decrease more than 2 points, limb weakness, onset of new neurological symptoms
\end{tabular}

\begin{tabular}{ll}
\hline Rx: unspecified LMWH SC (0.4 mL 4100 anti-Xa IU twice daily) \\
Control: heparin (5000 IU bolus, then 15,000 IU/day for 24 hours, then dose adjusted to maintain APTT \\
ratio at 1.5 to 2$)$ \\
Duration: 10 days
\end{tabular}

\begin{tabular}{ll}
\hline Outcomes & Haemorrhagic transformation (systematic CT on day 10 or symptomatic before day 10) \\
& Barthel Index
\end{tabular}

Notes
FU: 28 days

\section{Risk of bias}

Low-molecular-weight heparins or heparinoids versus standard unfractionated heparin for acute ischaemic stroke (Review) 
Wong 2000 (Continued)

\begin{tabular}{|c|c|c|}
\hline Bias & Authors' judgement & Support for judgement \\
\hline $\begin{array}{l}\text { Random sequence genera- } \\
\text { tion (selection bias) }\end{array}$ & Unclear risk & Not stated \\
\hline $\begin{array}{l}\text { Allocation concealment } \\
\text { (selection bias) }\end{array}$ & Unclear risk & Not stated \\
\hline $\begin{array}{l}\text { Blinding of participants } \\
\text { and personnel (perfor- } \\
\text { mance bias) } \\
\text { All outcomes }\end{array}$ & Unclear risk & not stated \\
\hline $\begin{array}{l}\text { Blinding of outcome as- } \\
\text { sessment (detection bias) } \\
\text { All outcomes }\end{array}$ & Unclear risk & Not stated \\
\hline $\begin{array}{l}\text { Incomplete outcome data } \\
\text { (attrition bias) } \\
\text { All outcomes }\end{array}$ & Unclear risk & Not stated \\
\hline $\begin{array}{l}\text { Selective reporting (re- } \\
\text { porting bias) }\end{array}$ & Unclear risk & $\begin{array}{l}\text { Study protocol not available, study report does not give full details of data col- } \\
\text { lected during follow-up }\end{array}$ \\
\hline
\end{tabular}

APTT: activated partial thromboplastin time

BP: blood pressure

$\mathrm{CT}$ : computerised tomography

DVT: deep venous thrombosis

Ex: exclusion criteria

FU: follow up

GCS: Glasgow coma scale

ITT: intention-to-treat

iv: intravenously

LMWH: low-molecular-weight heparin

MRI: magnetic resonance imaging

mRS: ???

NIHSS: National Institutes of Health stroke Scale

PE: pulmonary embolism

R: randomisation method

Rx: treatment

sc: subcutaneously

TCD: transcranial doppler

Characteristics of excluded studies [ordered by study ID]

\begin{tabular}{ll}
\hline Study & Reason for exclusion \\
\hline Assadian 2008 & Target participants were not people with acute ischaemic stroke \\
\hline Dunatov 2008 & Intervention did not include unfractionated heparin \\
\hline EMSG 1996 & $\begin{array}{l}\text { Enoxaparin } 20 \text { mg subcutaneously once daily versus standard unfractionated heparin } 5000 \text { IU sub- } \\
\text { cutaneously twice daily for } 10 \text { days in immobile people (38 strokes) } \\
\text { Data on subset of participants with stroke are still awaited from sponsor }\end{array}$ \\
\hline EUROTOAST 1996 & Comparison of different doses of heparinoid, no UFH group \\
\hline
\end{tabular}




\begin{tabular}{|c|c|}
\hline Study & Reason for exclusion \\
\hline EXCLAIM 2010 & Target participants were not people with acute ischaemic stroke \\
\hline Feiz 2016 & 2 treatment groups confounded by co-administration of different warfarin regimens \\
\hline Geng 2004 & Intervention did not include UFH \\
\hline Harenberg 1999 & $\begin{array}{l}\text { Enoxaparin versus heparin for prophylaxis of thromboembolic events in people with medical con- } \\
\text { ditions } \\
\text { Data have not been reported separately for people with stroke alone }\end{array}$ \\
\hline Heparinas 2013 & Ongoing trial of heparin versus nadroparin versus placebo. Complex confounded regimens \\
\hline HESIM 1990 & $\begin{array}{l}\text { About } 150(19 \%) \text { participants had neurological disease } \\
\text { Data have not been reported separately for people with stroke alone } \\
\text { Some data may be the same as those reported in Harenberg } 1999\end{array}$ \\
\hline IRCT201109067495N1 & Comparison of LMWH with aspirin instead of UFH \\
\hline MAGELLAN 2013 & Intervention did not include UFH \\
\hline McCarthy 1993 & Data have not been reported \\
\hline Mikulik 2006 & Intervention did not include UFH \\
\hline Moulin 1994 & $\begin{array}{l}\text { Enoxaparin/CY216 versus standard UFH } \\
\text { The trial was closed prematurely due to funding constraints } \\
\text { Data have not been reported }\end{array}$ \\
\hline NCT01763606 & Target participants were not people with acute ischaemic stroke \\
\hline Necioglu Orken 2009 & Intervention did not include UFH \\
\hline Nikc Evic 2006 & Not acute stroke, method of treatment allocation not random \\
\hline Szirmai 1986 & Uncontrolled study \\
\hline Tan 2002 & $\begin{array}{l}\text { Published in China and only available as an abstract. Attempted to contact authors as well as seek } \\
\text { help from colleagues from China to obtain the full text article but to no avail }\end{array}$ \\
\hline Trencev 2008 & Intervention did not include UFH \\
\hline Trouillas 2008 & Intervention did not include LMWH \\
\hline Wang 2012 & $\begin{array}{l}\text { Published in China and only available as an abstract. Attempted to contact authors as well as seek } \\
\text { help from colleagues from China to obtain the full text article but to no avail }\end{array}$ \\
\hline Xing 2006 & Intervention did not include UFH \\
\hline
\end{tabular}

LMWH: low-molecular-weight heparin

UFH: unfractionated heparin

Characteristics of ongoing studies [ordered by study ID] 
Aventis 2002

$\begin{array}{ll}\text { Trial name or title } & \begin{array}{l}\text { An open-label, randomised, parallel group, multicentre study to evaluate the efficacy and safety of } \\ \text { enoxaparin versus unfractionated heparin in the prevention of venous thromboembolism in peo- } \\ \text { ple following acute ischaemic stroke }\end{array}\end{array}$

Methods

Participants

Interventions

Outcomes

Starting date

Contact information

Ms S Wellington, Senior Clinical Project Leader, Aventis Pharma, Aventis House, 50 Kings Hill Avenue, Kings Hill, West Malling, Kent, UK

Notes

Young 2001

Trial name or title

Low-molecular-weight heparin (enoxaparin) in anticoagulation transition to oral warfarin in ischaemic cerebral vascular accident or transient ischaemic attack

\begin{tabular}{ll}
\hline Methods & Acute ischaemic stroke \\
\hline Participants & Enoxaparin sc + oral warfarin versus UFH sc + oral warfarin \\
\hline Interventions & \\
\hline Outcomes & Dr WD Young, North Mississippi Medical Centre, 830 S Gloster Street, Tupelo MS 38801, USA \\
\hline Starting date & \\
\hline Nontact information &
\end{tabular}

sc: subcutaneously

UFH: unfractionated heparin

\section{DATA AND ANALYSES}

\section{Comparison 1. LMWH/heparinoid versus standard UFH in acute ischaemic stroke}

\begin{tabular}{lllll}
\hline Outcome or subgroup title & No. of studies & $\begin{array}{l}\text { No. of partici- } \\
\text { pants }\end{array}$ & Statistical method & Effect size \\
\hline $\begin{array}{l}\text { 1 Dead or dependent at the end of fol- } \\
\text { low-up }\end{array}$ & 0 & 0 & $\begin{array}{l}\text { Odds Ratio (M-H, Fixed, 95\% } \\
\text { Cl) }\end{array}$ & $0.0[0.0,0.0]$ \\
\hline
\end{tabular}




\begin{tabular}{|c|c|c|c|c|}
\hline Outcome or subgroup title & No. of studies & $\begin{array}{l}\text { No. of partici- } \\
\text { pants }\end{array}$ & Statistical method & Effect size \\
\hline $\begin{array}{l}2 \text { Death from all causes during treat- } \\
\text { ment period }\end{array}$ & 8 & 3102 & $\begin{array}{l}\text { Peto Odds Ratio (Peto, Fixed, } \\
95 \% \mathrm{Cl} \text { ) }\end{array}$ & $1.06[0.78,1.46]$ \\
\hline 2.1 Heparinoid versus standard UFH & 4 & 493 & $\begin{array}{l}\text { Peto Odds Ratio (Peto, Fixed, } \\
95 \% \mathrm{Cl} \text { ) }\end{array}$ & $1.19[0.62,2.26]$ \\
\hline 2.2 LMWH versus standard UFH & 4 & 2609 & $\begin{array}{l}\text { Peto Odds Ratio (Peto, Fixed, } \\
95 \% \mathrm{CI} \text { ) }\end{array}$ & $1.03[0.72,1.47]$ \\
\hline $\begin{array}{l}3 \text { Death from all causes during fol- } \\
\text { low-up }\end{array}$ & 8 & 3102 & $\begin{array}{l}\text { Peto Odds Ratio (Peto, Fixed, } \\
95 \% \mathrm{Cl} \text { ) }\end{array}$ & $0.98[0.79,1.23]$ \\
\hline 3.1 Heparinoid versus standard UFH & 4 & 493 & $\begin{array}{l}\text { Peto Odds Ratio (Peto, Fixed, } \\
95 \% \mathrm{Cl} \text { ) }\end{array}$ & $1.16[0.69,1.94]$ \\
\hline 3.2 LMWH versus standard UFH & 4 & 2609 & $\begin{array}{l}\text { Peto Odds Ratio (Peto, Fixed, } \\
95 \% \mathrm{Cl} \text { ) }\end{array}$ & $0.95[0.74,1.21]$ \\
\hline 4 Vascular death during follow-up & 5 & 1038 & $\begin{array}{l}\text { Peto Odds Ratio (Peto, Fixed, } \\
95 \% \mathrm{Cl} \text { ) }\end{array}$ & $1.15[0.72,1.85]$ \\
\hline 4.1 Heparinoid versus standard UFH & 4 & 493 & $\begin{array}{l}\text { Peto Odds Ratio (Peto, Fixed, } \\
95 \% \mathrm{Cl} \text { ) }\end{array}$ & $1.15[0.68,1.94]$ \\
\hline 4.2 LMWH versus standard UFH & 1 & 545 & $\begin{array}{l}\text { Peto Odds Ratio (Peto, Fixed, } \\
95 \% \mathrm{CI} \text { ) }\end{array}$ & $1.17[0.39,3.53]$ \\
\hline $\begin{array}{l}5 \text { Deep venous thrombosis during } \\
\text { treatment period }\end{array}$ & 7 & 2585 & $\begin{array}{l}\text { Peto Odds Ratio (Peto, Fixed, } \\
95 \% \mathrm{Cl} \text { ) }\end{array}$ & $0.55[0.44,0.70]$ \\
\hline 5.1 Heparinoid versus standard UFH & 4 & 493 & $\begin{array}{l}\text { Peto Odds Ratio (Peto, Fixed, } \\
95 \% \mathrm{Cl} \text { ) }\end{array}$ & $0.52[0.31,0.86]$ \\
\hline 5.2 LMWH versus standard UFH & 3 & 2092 & $\begin{array}{l}\text { Peto Odds Ratio (Peto, Fixed, } \\
95 \% \mathrm{Cl} \text { ) }\end{array}$ & $0.56[0.44,0.73]$ \\
\hline $\begin{array}{l}6 \text { Pulmonary embolism during fol- } \\
\text { low-up }\end{array}$ & 6 & 1250 & $\begin{array}{l}\text { Peto Odds Ratio (Peto, Fixed, } \\
95 \% \mathrm{Cl} \text { ) }\end{array}$ & $0.57[0.23,1.41]$ \\
\hline 6.1 Heparinoid versus standard UFH & 4 & 493 & $\begin{array}{l}\text { Peto Odds Ratio (Peto, Fixed, } \\
95 \% \mathrm{Cl} \text { ) }\end{array}$ & $0.64[0.18,2.21]$ \\
\hline 6.2 LMWH versus standard UFH & 2 & 757 & $\begin{array}{l}\text { Peto Odds Ratio (Peto, Fixed, } \\
95 \% \mathrm{Cl} \text { ) }\end{array}$ & $0.51[0.13,1.90]$ \\
\hline $\begin{array}{l}7 \text { Any intracranial haemorrhage/haem- } \\
\text { orrhagic transformation of the cerebral } \\
\text { infarct during treatment period }\end{array}$ & 9 & 3137 & $\begin{array}{l}\text { Peto Odds Ratio (Peto, Fixed, } \\
95 \% \mathrm{Cl} \text { ) }\end{array}$ & $0.75[0.46,1.23]$ \\
\hline 7.1 Heparinoid versus standard UFH & 4 & 493 & $\begin{array}{l}\text { Peto Odds Ratio (Peto, Fixed, } \\
95 \% \mathrm{Cl} \text { ) }\end{array}$ & $1.12[0.43,2.94]$ \\
\hline 7.2 LMWH versus standard UFH & 5 & 2644 & $\begin{array}{l}\text { Peto Odds Ratio (Peto, Fixed, } \\
95 \% \mathrm{Cl} \text { ) }\end{array}$ & $0.66[0.37,1.15]$ \\
\hline
\end{tabular}




\begin{tabular}{|c|c|c|c|c|}
\hline Outcome or subgroup title & No. of studies & $\begin{array}{l}\text { No. of partici- } \\
\text { pants }\end{array}$ & Statistical method & Effect size \\
\hline $\begin{array}{l}8 \text { Symptomatic intracranial haemor- } \\
\text { rhage/haemorrhagic transformation of } \\
\text { the infarct during treatment period }\end{array}$ & 8 & 3102 & $\begin{array}{l}\text { Peto Odds Ratio (Peto, Fixed, } \\
95 \% \mathrm{Cl} \text { ) }\end{array}$ & $0.73[0.35,1.54]$ \\
\hline 8.1 Heparinoid versus standard UFH & 4 & 493 & $\begin{array}{l}\text { Peto Odds Ratio (Peto, Fixed, } \\
95 \% \mathrm{Cl} \text { ) }\end{array}$ & $0.90[0.19,4.40]$ \\
\hline 8.2 LMWH versus standard UFH & 4 & 2609 & $\begin{array}{l}\text { Peto Odds Ratio (Peto, Fixed, } \\
95 \% \mathrm{CI} \text { ) }\end{array}$ & $0.69[0.30,1.60]$ \\
\hline $\begin{array}{l}9 \text { Extracranial haemorrhage during } \\
\text { treatment period }\end{array}$ & 7 & & $\begin{array}{l}\text { Peto Odds Ratio (Peto, Fixed, } \\
95 \% \mathrm{Cl} \text { ) }\end{array}$ & Subtotals only \\
\hline 9.1 Major extracranial haemorrhage & 7 & 3012 & $\begin{array}{l}\text { Peto Odds Ratio (Peto, Fixed, } \\
95 \% \mathrm{CI} \text { ) }\end{array}$ & $3.79[1.30,11.06]$ \\
\hline 9.2 Minor extracranial haemorrhage & 7 & 3012 & $\begin{array}{l}\text { Peto Odds Ratio (Peto, Fixed, } \\
95 \% \mathrm{Cl} \text { ) }\end{array}$ & $0.91[0.67,1.24]$ \\
\hline $\begin{array}{l}10 \text { Effect of recurrent ischaemic stroke } \\
\text { or recurrent stroke of unknown patho- } \\
\text { logical type during treatment period }\end{array}$ & 2 & 1839 & $\begin{array}{l}\text { Peto Odds Ratio (Peto, Fixed, } \\
95 \% \mathrm{Cl} \text { ) }\end{array}$ & $1.94[0.61,6.11]$ \\
\hline 10.1 LMWH versus UFH & 2 & 1839 & $\begin{array}{l}\text { Peto Odds Ratio (Peto, Fixed, } \\
95 \% \mathrm{Cl} \text { ) }\end{array}$ & $1.94[0.61,6.11]$ \\
\hline $\begin{array}{l}11 \text { Deep venous thrombosis according } \\
\text { to heparinoid dosage regimen }\end{array}$ & 4 & & $\begin{array}{l}\text { Peto Odds Ratio (Peto, Fixed, } \\
95 \% \mathrm{Cl} \text { ) }\end{array}$ & Subtotals only \\
\hline $\begin{array}{l}11.1350 \text { anti-Xa units } 24 \text {-hourly versus } \\
5000 \text { IU UFH } 12 \text {-hourly }\end{array}$ & 1 & 60 & $\begin{array}{l}\text { Peto Odds Ratio (Peto, Fixed, } \\
95 \% \mathrm{CI} \text { ) }\end{array}$ & $2.11[0.67,6.59]$ \\
\hline $\begin{array}{l}11.2750 \text { anti-Xa units } 24 \text {-hourly versus } \\
5000 \text { IU UFH } 12 \text {-hourly }\end{array}$ & 1 & 72 & $\begin{array}{l}\text { Peto Odds Ratio (Peto, Fixed, } \\
95 \% \mathrm{Cl} \text { ) }\end{array}$ & $0.54[0.14,2.14]$ \\
\hline $\begin{array}{l}11.31250 \text { anti-Xa units } 24 \text {-hourly ver- } \\
\text { sus } 5000 \text { IU UFH 12-hourly }\end{array}$ & 2 & 246 & $\begin{array}{l}\text { Peto Odds Ratio (Peto, Fixed, } \\
95 \% \mathrm{Cl} \text { ) }\end{array}$ & $0.63[0.32,1.26]$ \\
\hline $\begin{array}{l}11.4750 \text { anti-Xa units } 12 \text {-hourly versus } \\
5000 \text { IU UFH } 12 \text {-hourly }\end{array}$ & 2 & 140 & $\begin{array}{l}\text { Peto Odds Ratio (Peto, Fixed, } \\
95 \% \mathrm{Cl} \text { ) }\end{array}$ & $0.30[0.13,0.71]$ \\
\hline $\begin{array}{l}11.51250 \text { anti-Xa units 12-hourly ver- } \\
\text { sus } 5000 \text { IU UFH 12-hourly }\end{array}$ & 1 & 55 & $\begin{array}{l}\text { Peto Odds Ratio (Peto, Fixed, } \\
95 \% \mathrm{Cl} \text { ) }\end{array}$ & $0.28[0.06,1.23]$ \\
\hline $\begin{array}{l}12 \text { Intracranial and extracranial haem- } \\
\text { orrhage during treatment according to } \\
\text { dosage regimen }\end{array}$ & 4 & & $\begin{array}{l}\text { Peto Odds Ratio (Peto, Fixed, } \\
95 \% \mathrm{Cl} \text { ) }\end{array}$ & Subtotals only \\
\hline $\begin{array}{l}12.1350 \text { anti-Xa units } 24 \text {-hourly versus } \\
5000 \text { IU UFH } 12 \text {-hourly }\end{array}$ & 1 & 60 & $\begin{array}{l}\text { Peto Odds Ratio (Peto, Fixed, } \\
95 \% \mathrm{Cl} \text { ) }\end{array}$ & $1.29[0.45,3.68]$ \\
\hline $\begin{array}{l}12.2750 \text { anti-Xa units } 24 \text {-hourly versus } \\
5000 \text { IU UFH } 12 \text {-hourly }\end{array}$ & 1 & 72 & $\begin{array}{l}\text { Peto Odds Ratio (Peto, Fixed, } \\
95 \% \mathrm{Cl} \text { ) }\end{array}$ & $0.90[0.33,2.50]$ \\
\hline
\end{tabular}




\begin{tabular}{lllll}
\hline Outcome or subgroup title & No. of studies & $\begin{array}{l}\text { No. of partici- } \\
\text { pants }\end{array}$ & Statistical method & Effect size \\
\hline $\begin{array}{l}\text { 12.3 1250 anti-Xa units 24-hourly ver- } \\
\text { sus 5000 IU UFH 12-hourly }\end{array}$ & 2 & 246 & $\begin{array}{l}\text { Peto Odds Ratio (Peto, Fixed, } \\
95 \% \text { Cl) }\end{array}$ & 0.69 [0.38, 1.25] \\
\hline $\begin{array}{l}12.4750 \text { anti-Xa units 12-hourly versus } \\
\text { 5000 IU UFH 12-hourly }\end{array}$ & 2 & 138 & $\begin{array}{l}\text { Peto Odds Ratio (Peto, Fixed, } \\
95 \% \text { Cl) }\end{array}$ & $2.73[1.03,7.24]$ \\
\hline $\begin{array}{l}\text { 12.5 1250 anti-Xa units 12-hourly ver- } \\
\text { sus 5000 IU UFH 12-hourly }\end{array}$ & 1 & 53 & $\begin{array}{l}\text { Peto Odds Ratio (Peto, Fixed, } \\
95 \% \text { Cl) }\end{array}$ & $1.71[0.31,9.25]$ \\
\hline
\end{tabular}

Analysis 1.2. Comparison $1 \mathrm{LMWH} /$ heparinoid versus standard UFH in acute ischaemic stroke, Outcome 2 Death from all causes during treatment period.

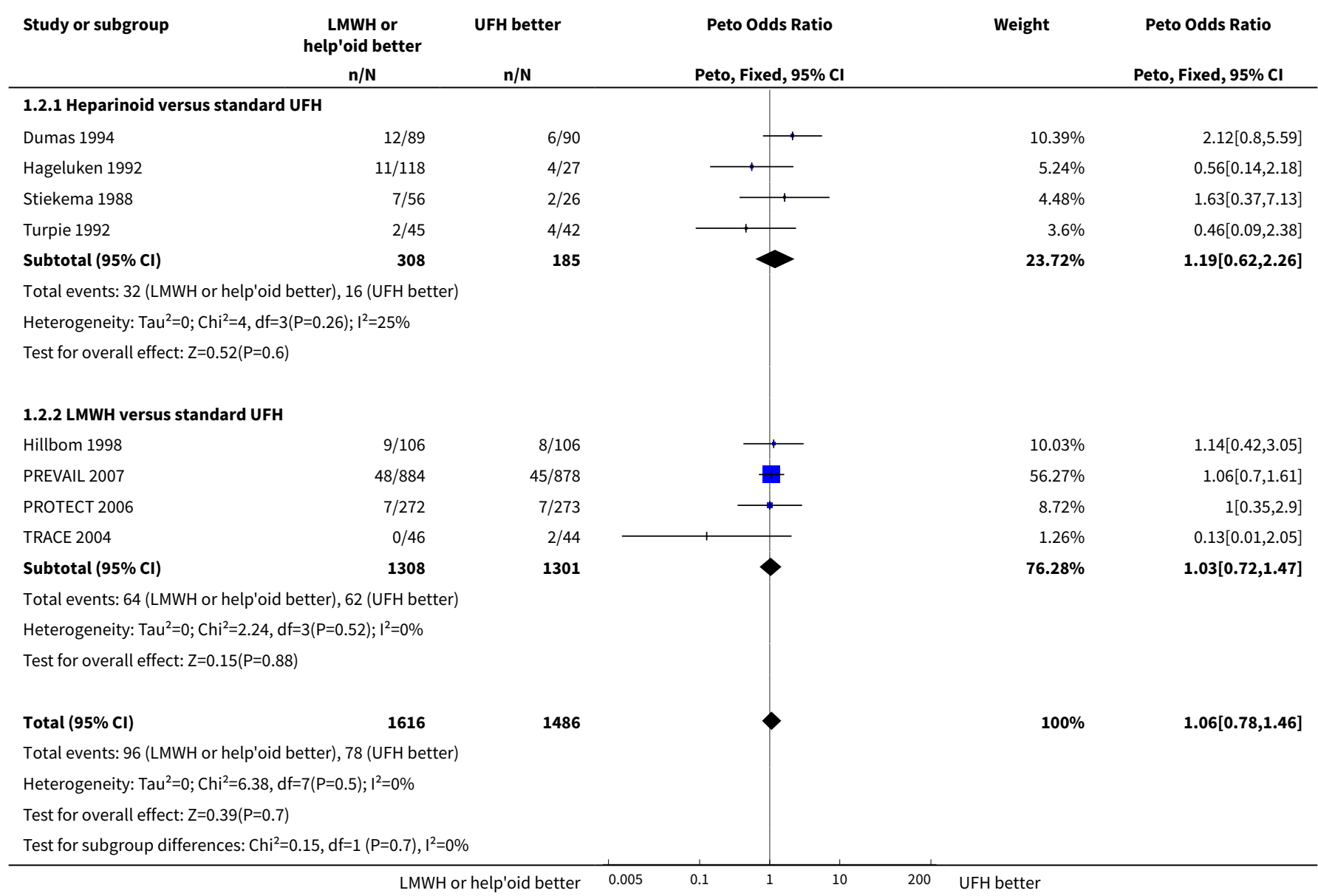


Analysis 1.3. Comparison $1 \mathrm{LMWH} / \mathrm{heparinoid} \mathrm{versus} \mathrm{standard} \mathrm{UFH} \mathrm{in}$ acute ischaemic stroke, Outcome 3 Death from all causes during follow-up.

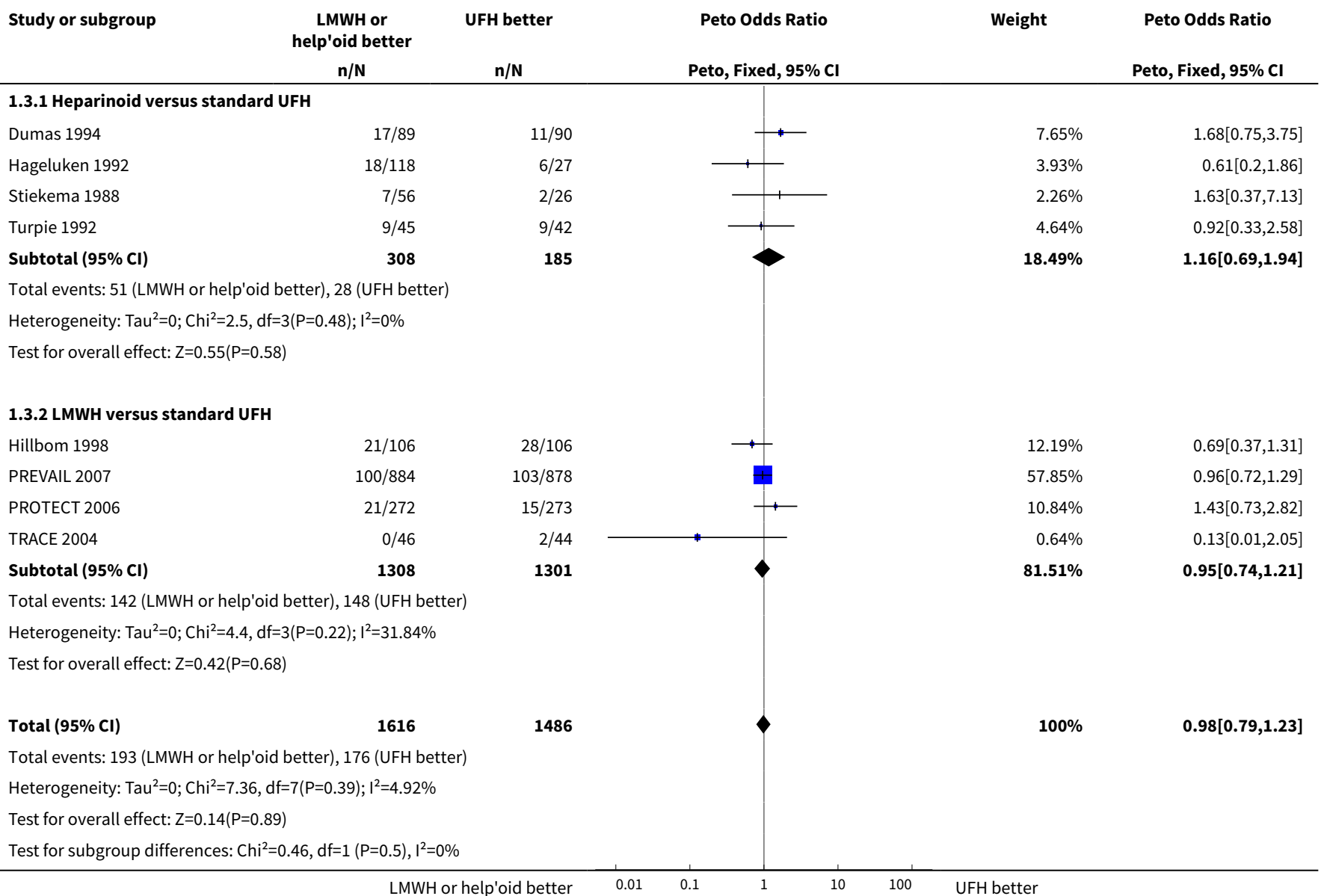

\section{Analysis 1.4. Comparison $1 \mathrm{LMWH} / \mathrm{heparinoid} \mathrm{versus} \mathrm{standard} \mathrm{UFH} \mathrm{in}$ acute ischaemic stroke, Outcome 4 Vascular death during follow-up.}

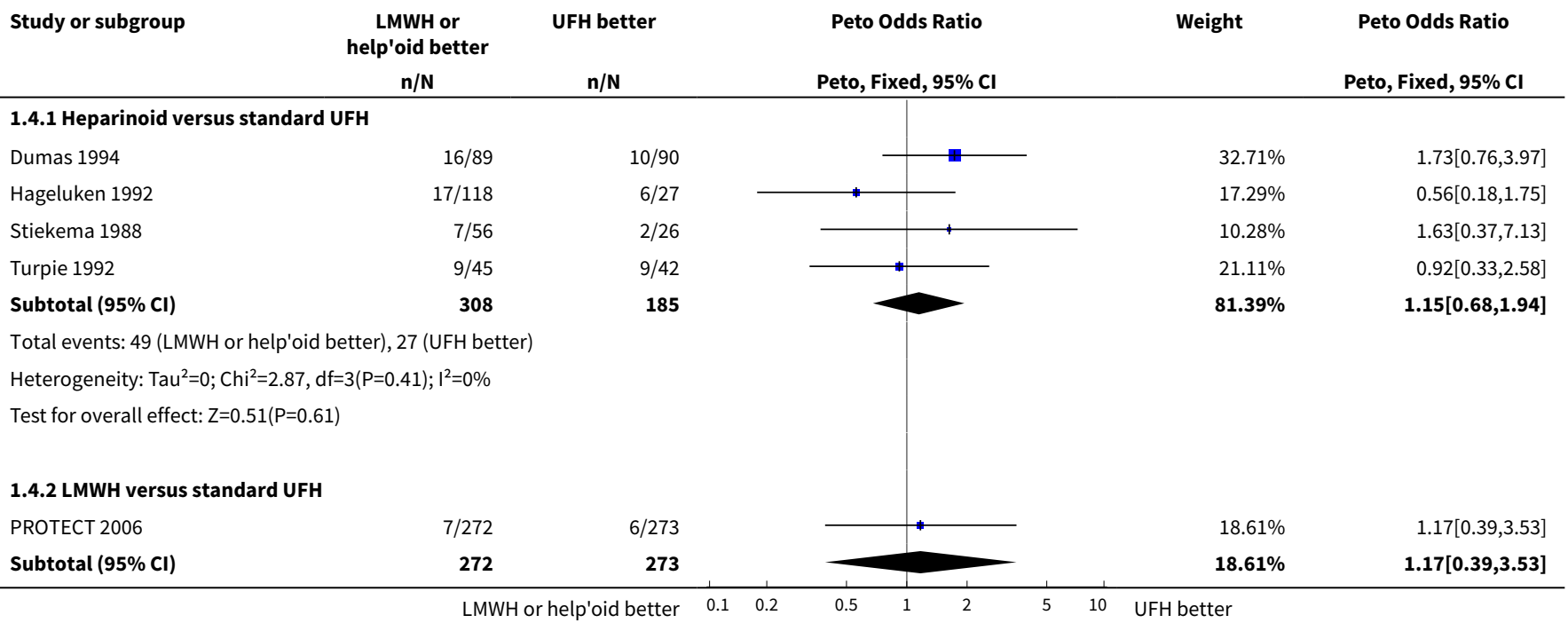




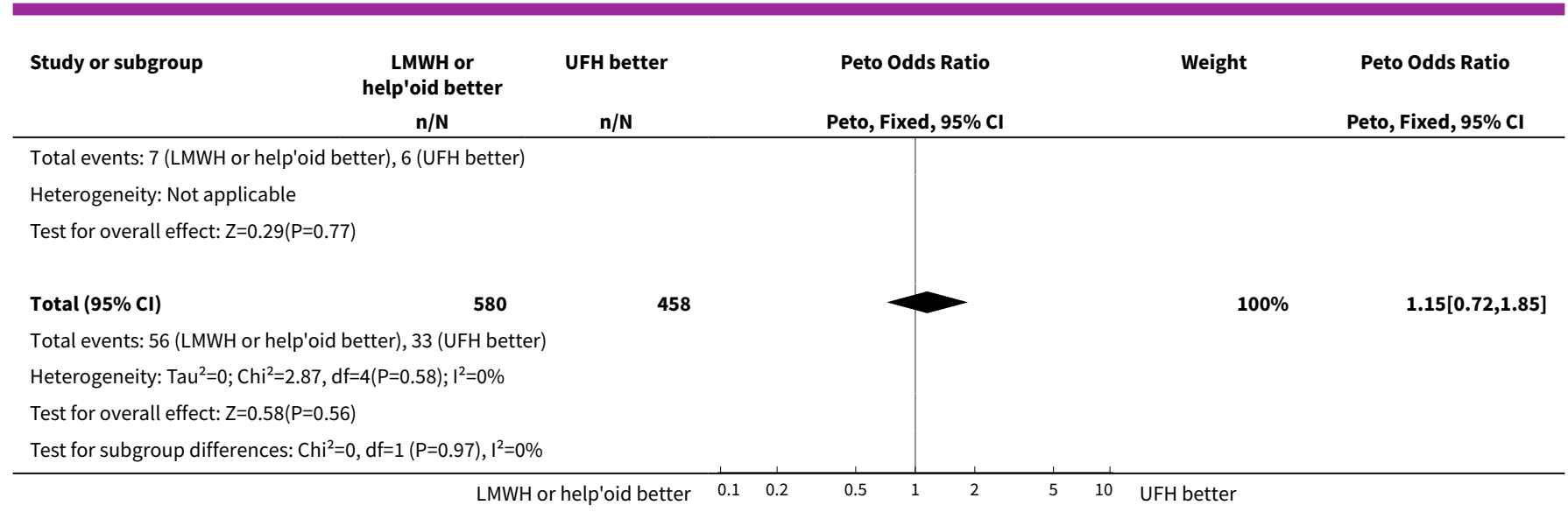

Analysis 1.5. Comparison $1 \mathrm{LMWH} /$ heparinoid versus standard UFH in acute ischaemic stroke, Outcome 5 Deep venous thrombosis during treatment period.

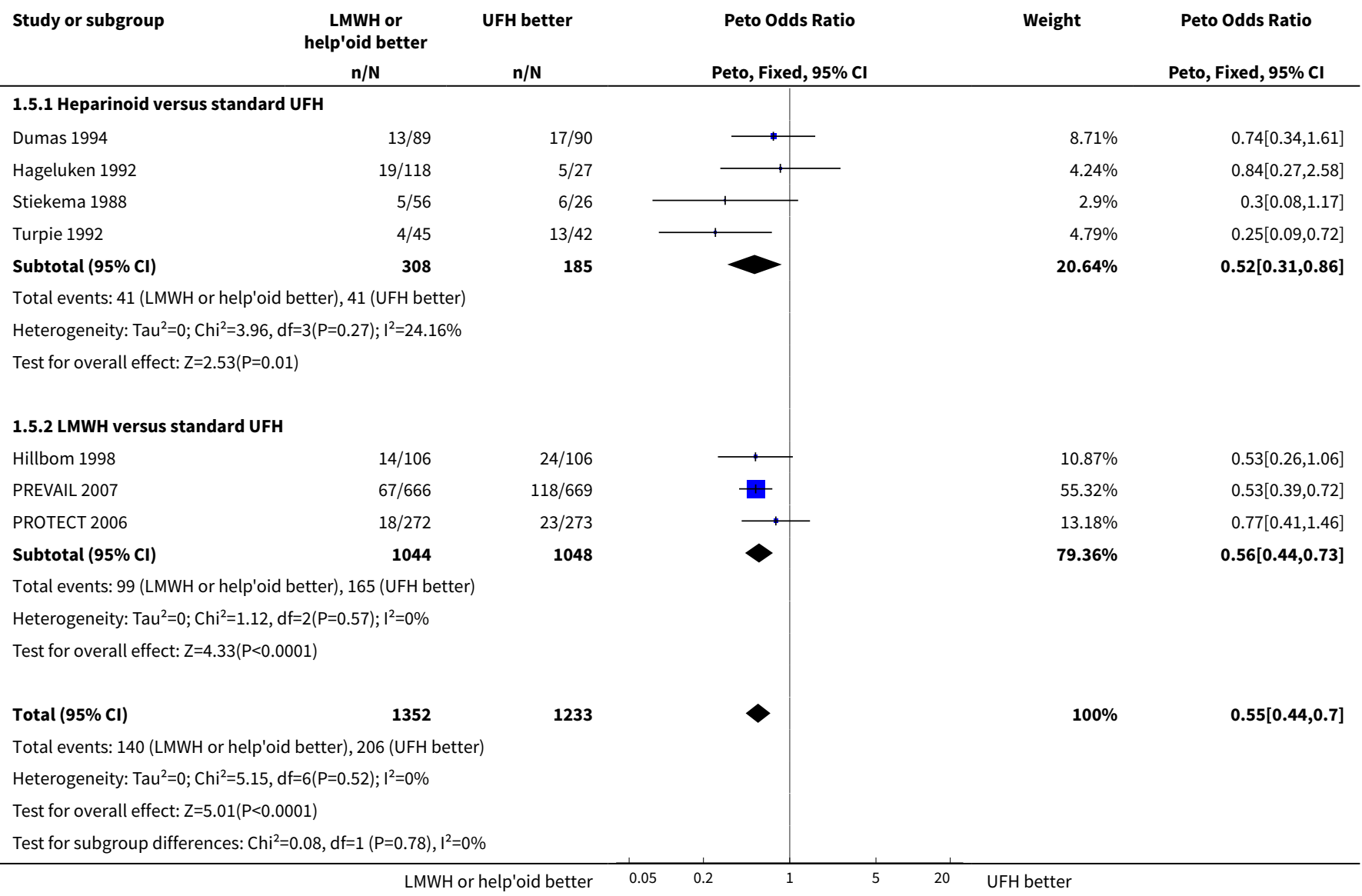


Analysis 1.6. Comparison $1 \mathrm{LMWH} / \mathrm{heparinoid} \mathrm{versus} \mathrm{standard} \mathrm{UFH} \mathrm{in}$ acute ischaemic stroke, Outcome 6 Pulmonary embolism during follow-up.

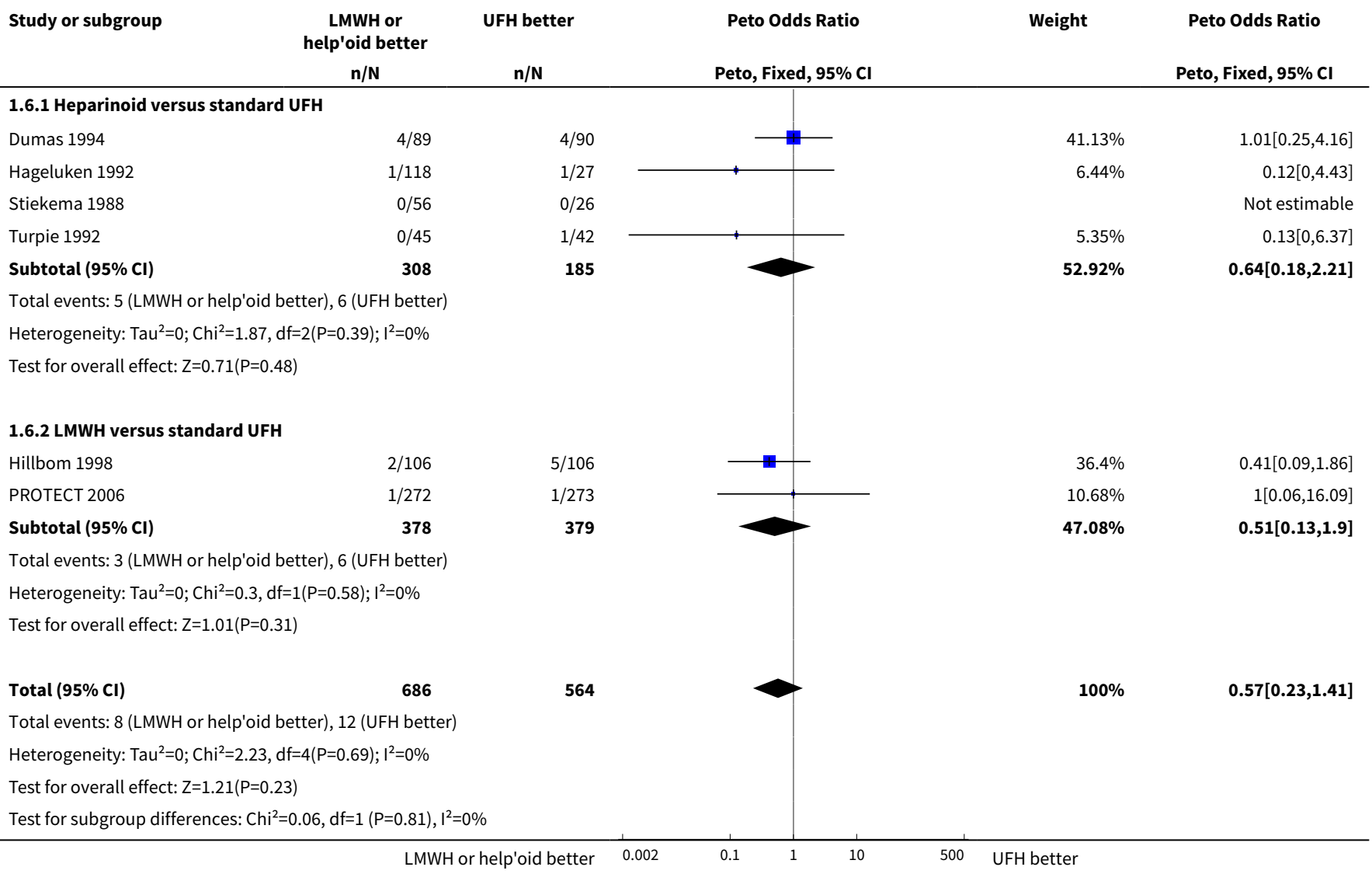

Analysis 1.7. Comparison 1 LMWH/heparinoid versus standard UFH in acute ischaemic stroke, Outcome 7 Any intracranial haemorrhage/haemorrhagic transformation of the cerebral infarct during treatment period.

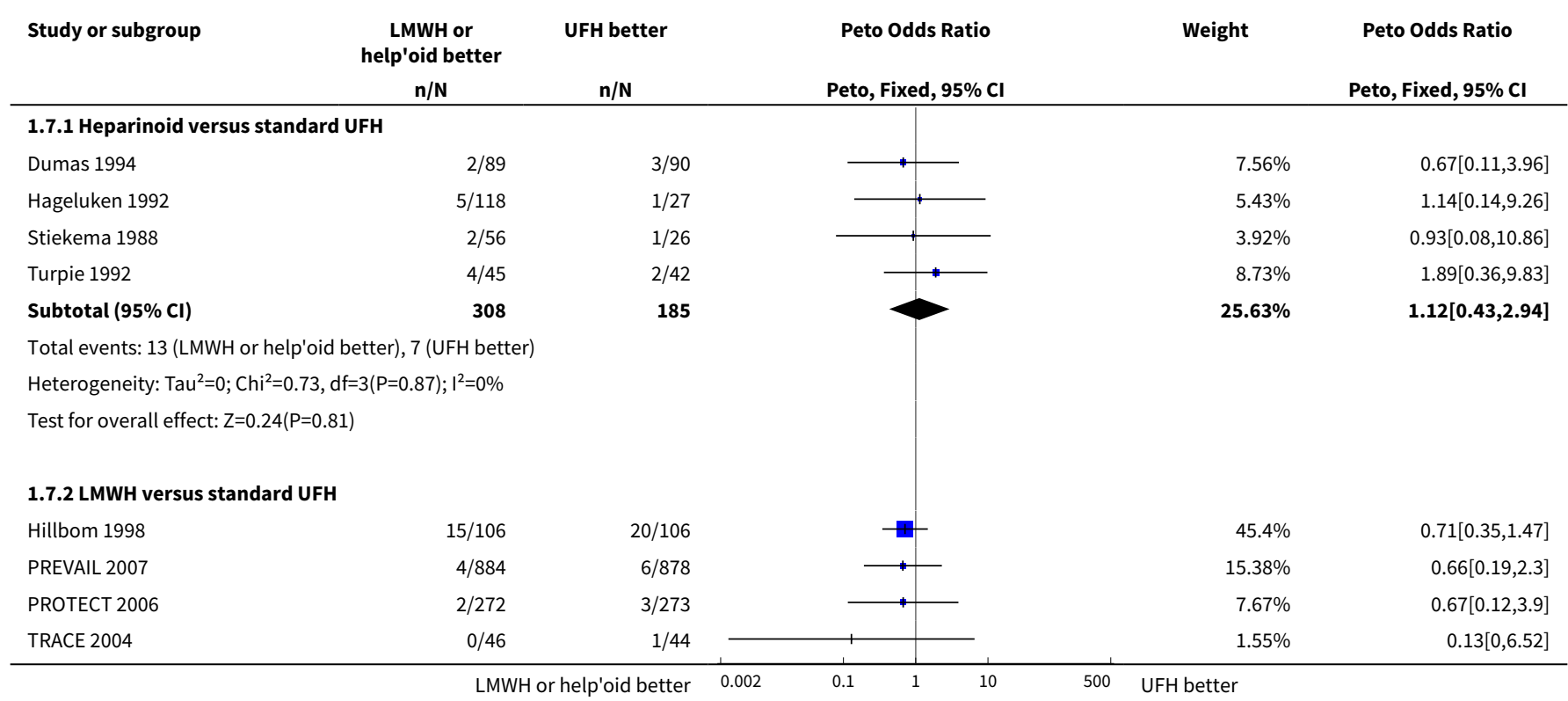




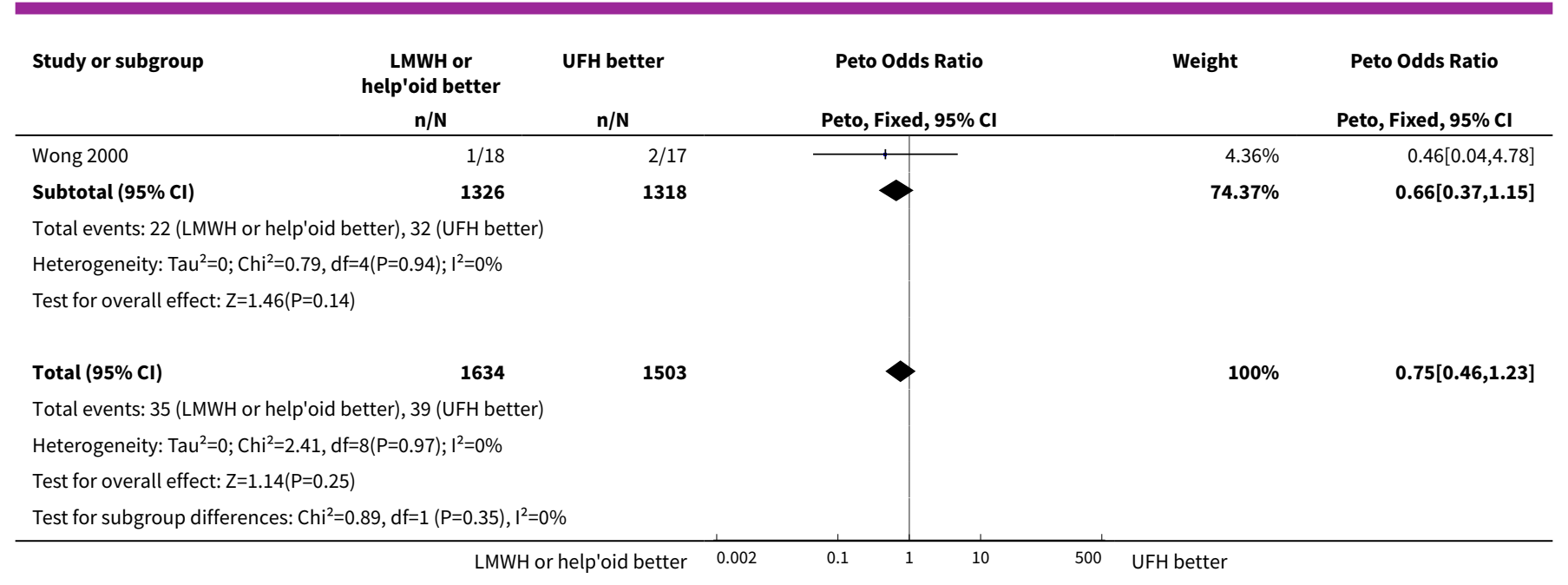

Analysis 1.8. Comparison $1 \mathrm{LMWH} /$ heparinoid versus standard UFH in acute ischaemic stroke, Outcome 8 Symptomatic intracranial haemorrhage/haemorrhagic transformation of the infarct during treatment period.

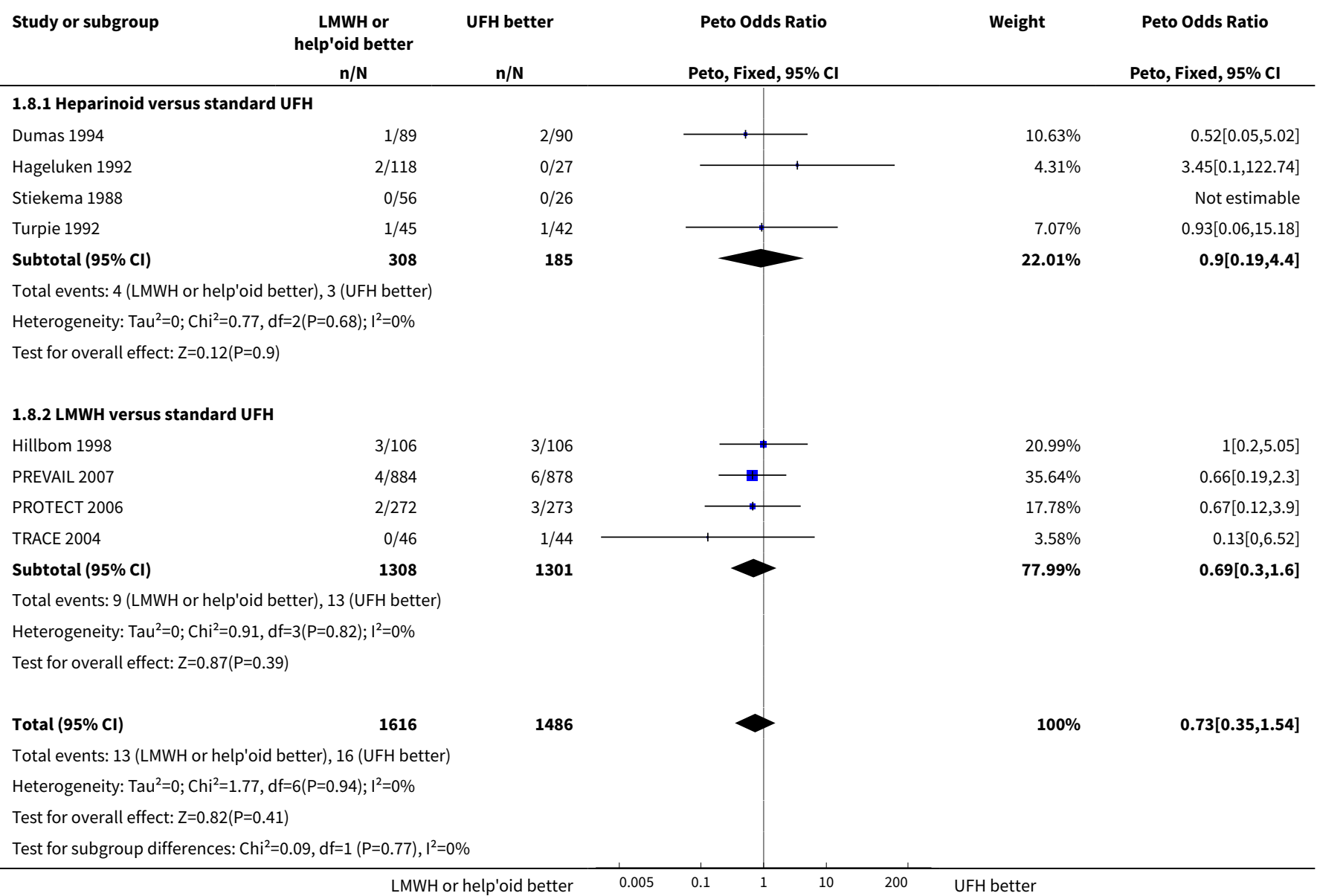


Analysis 1.9. Comparison $1 \mathrm{LMWH} /$ heparinoid versus standard UFH in acute ischaemic stroke, Outcome 9 Extracranial haemorrhage during treatment period.

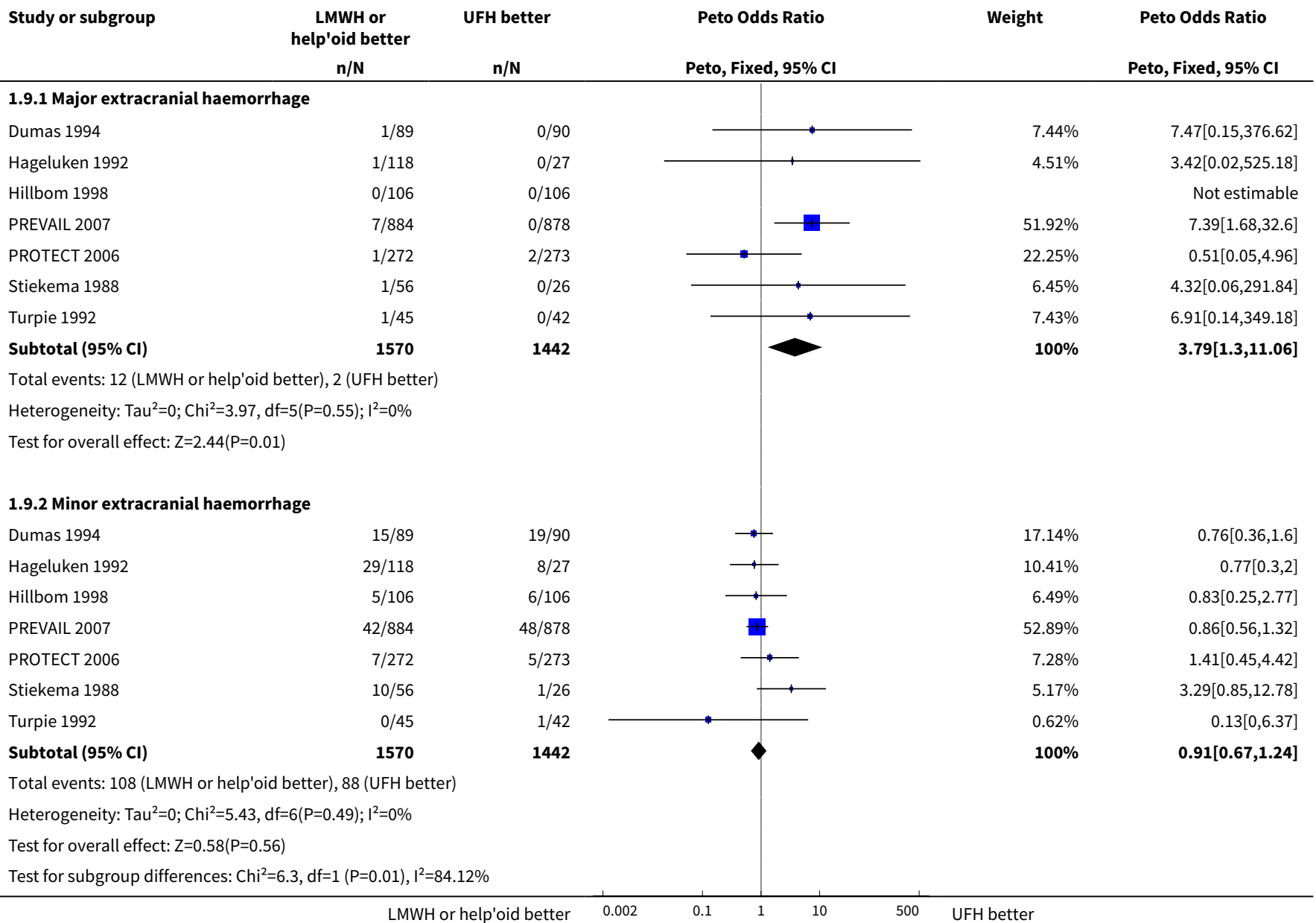

Analysis 1.10. Comparison $1 \mathrm{LMWH} /$ heparinoid versus standard UFH in acute ischaemic stroke, Outcome 10 Effect of recurrent ischaemic stroke or recurrent stroke of unknown pathological type during treatment period.

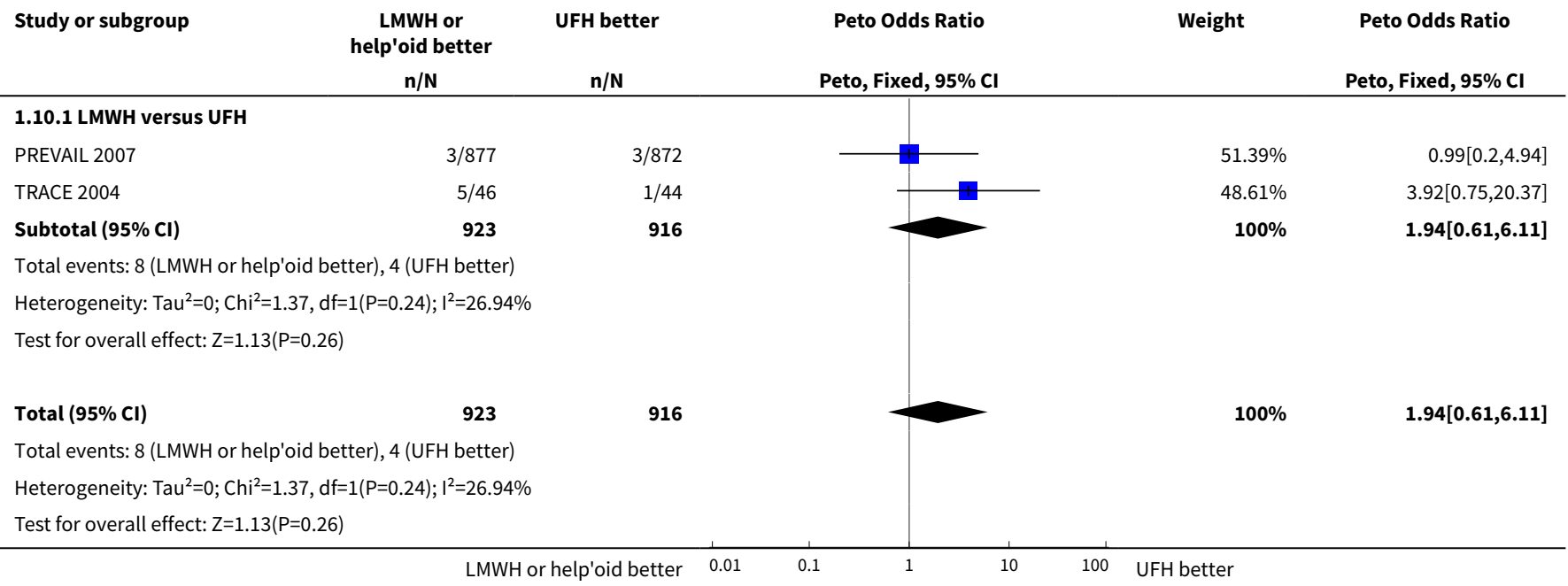


Analysis 1.11. Comparison $1 \mathrm{LMWH} /$ heparinoid versus standard UFH in acute ischaemic
stroke, Outcome 11 Deep venous thrombosis according to heparinoid dosage regimen.

Study or subgroup LMWH or
help'oid better UFH better Peto Odds Ratio

Weight Peto Odds Ratio $\mathrm{n} / \mathrm{N}$ $\mathbf{n} / \mathbf{N}$ Peto, Fixed, $95 \% \mathrm{Cl}$ Peto, Fixed, $95 \% \mathrm{Cl}$

1.11.1 350 anti-Xa units 24-hourly versus 5000 IU UFH 12-hourly Hageluken 1992

$11 / 33$

33 $5 / 27$

Subtotal $(95 \% \mathrm{Cl})$

27

$100 \%$

$100 \%$

$2.11[0.67,6.59]$

Total events: 11 (LMWH or help'oid better), 5 (UFH better)

Heterogeneity: Not applicable

Test for overall effect: $Z=1.28(P=0.2)$

1.11.2 750 anti-Xa units 24-hourly versus 5000 IU UFH 12-hourly Hageluken 1992

Total events: 5 (LMWH or help'oid better), 5 (UFH better)

Heterogeneity: Not applicable

Test for overall effect: $\mathrm{Z}=0.87(\mathrm{P}=0.38)$

1.11.3 1250 anti-Xa units 24-hourly versus 5000 IU UFH 12-hourly Dumas 1994

Total events: 16 (LMWH or help'oid better), 22 (UFH better) Heterogeneity: Tau $^{2}=0 ; \mathrm{Chi}^{2}=0.71, \mathrm{df}=1(\mathrm{P}=0.4) ; \mathrm{I}^{2}=0 \%$ Test for overall effect: $Z=1.31(P=0.19)$

1.11.4 750 anti-Xa units 12-hourly versus 5000 IU UFH 12-hourly Stiekema 1988 $3 / 27$

Turpie 1992 $4 / 45$ Subtotal $(95 \% \mathrm{CI})$ 72 $6 / 26$ $13 / 42$ 68

Total events: 7 (LMWH or help'oid better), 19 (UFH better) Heterogeneity: $\mathrm{Tau}^{2}=0 ; \mathrm{Chi}^{2}=0.38, \mathrm{df}=1(\mathrm{P}=0.54) ; \mathrm{I}^{2}=0 \%$ Test for overall effect: $Z=2.76(P=0.01)$

1.11.5 1250 anti-Xa units 12-hourly versus 5000 IU UFH 12-hourly Stiekema 1988 $2 / 29$

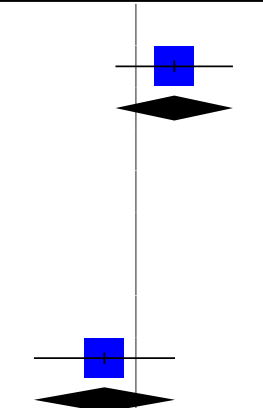

Total events: 2 (LMWH or help'oid better), 6 (UFH better)

Heterogeneity: Not applicable

Test for overall effect: $\mathrm{Z}=1.68(\mathrm{P}=0.09)$

Test for subgroup differences: $\mathrm{Chi}^{2}=8.13, \mathrm{df}=1(\mathrm{P}=0.09), \mathrm{I}^{2}=50.83 \%$

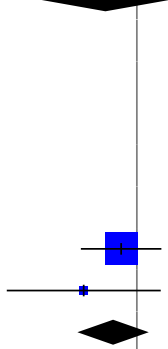

$78.49 \%$

$0.74[0.34,1.61]$

$0.63[0.32,1.26]$
$0.36[0.08,1.59]$
$0.43[0.11,1.8]$

$0.25[0.09,0.72]$

$64.48 \%$

$0.3[0.13,0.71]$ 
Analysis 1.12. Comparison $1 \mathrm{LMWH} /$ heparinoid versus standard UFH in acute ischaemic stroke, Outcome 12 Intracranial and extracranial haemorrhage during treatment according to dosage regimen.

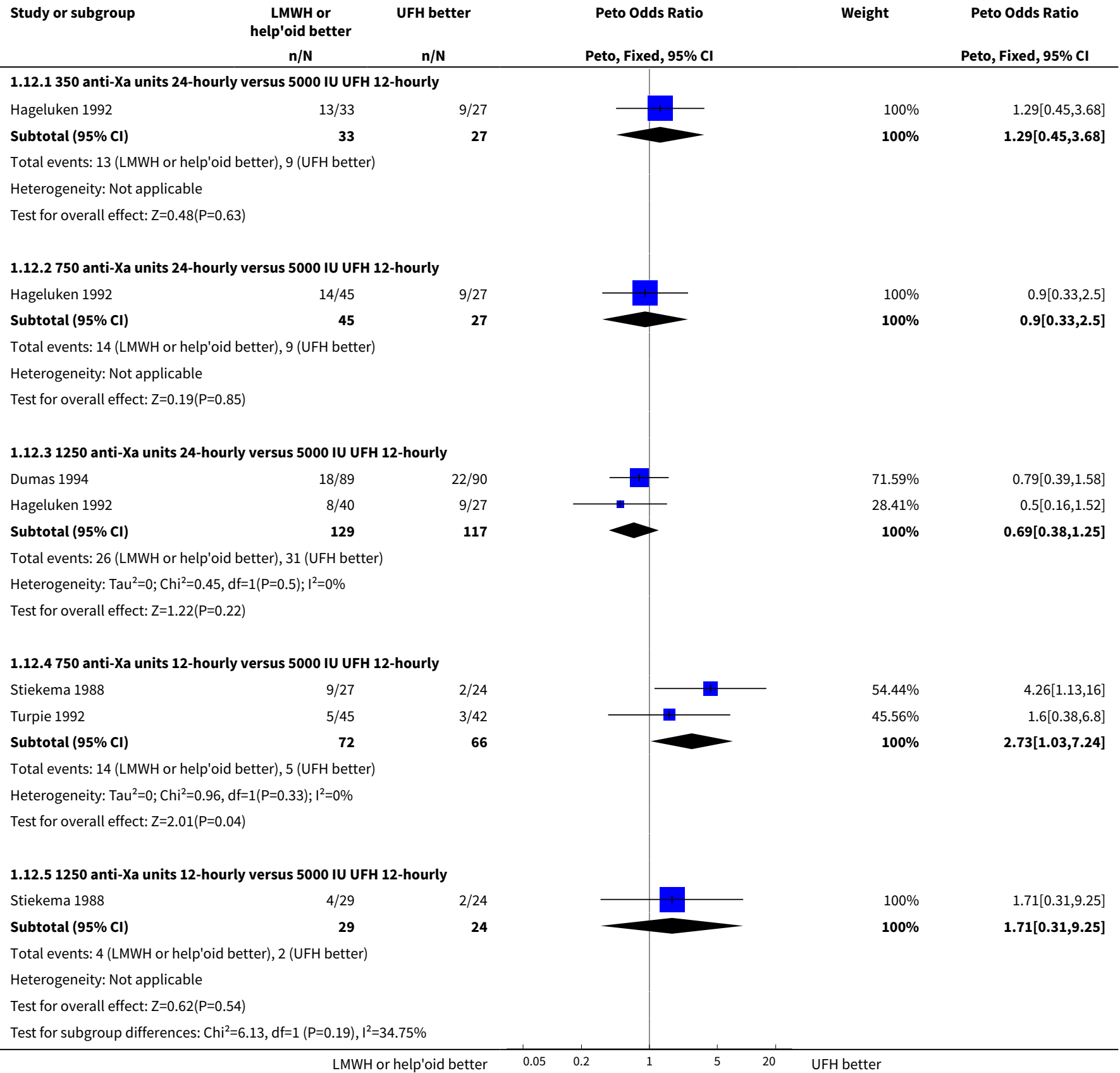

\section{APPENDICES}

\section{Appendix 1. CENTRAL}

Heparin AND Stroke

\section{Appendix 2. MEDLINE search strategy}

The following search strategy, using a combination of controlled vocabulary and text words, was used for MEDLINE and the Cochrane Central Register of Controlled Trials.

Low-molecular-weight heparins or heparinoids versus standard unfractionated heparin for acute ischaemic stroke (Review) 
1. cerebrovascular disorders/ or basal ganglia cerebrovascular disease/ or brain ischemia/ or carotid artery diseases/ or carotid artery thrombosis/ or cerebrovascular accident/ or exp brain infarction/ or exp hypoxia-ischemia, brain/ or intracranial arterial diseases/ or cerebral arterial diseases/ or exp "intracranial embolism and thrombosis"/

2. ((brain or cerebr $\$$ or cerebell\$ or vertebrobasil\$ or hemispher $\$$ or intracran $\$$ or intracerebral or infratentorial or supratentorial or middle cerebr\$ or mca\$ or anterior circulation) adj5 (isch?emi\$ or infarct\$ or thrombo or emboli\$ or occlus\$ or hypoxi\$)).tw.

3. (isch?emi\$ adj6 (stroke\$ or apoplex\$ or cerebral vasc\$ or cerebrovasc\$ or cva or attack\$)).tw.

4. 1 or 2 or 3

5. exp Heparin, Low-Molecular-Weight/

6. (low molecular weight heparin\$ or low-molecular-weight heparin\$ or Imwh\$).tw.

7. (antixarin or ardeparin or bemiparin or certoparin or cy 222 or dalteparin or embolex or enoxaparin or fondaparin\$ or idraparinux or monoembolex or nadroparin or parnaparin or rd 11885 or reviparin or tedelparin or tinzaparin).tw.

8. Heparinoids/

9. (heparinoid\$ or atheroid or danaparoid or org 10172 or mesoglycan or dermatan sul\$ or heparan sul\$ or pentosan polysul\$).tw.

10. or/5-9

11.4 and 10

\section{Appendix 3. Embase search strategy}

The following search strategy, using a combination of controlled vocabulary and text words, was used for EMBASE.

1. cerebrovascular disease/ or cerebral artery disease/ or cerebrovascular accident/ or stroke/ or carotid artery disease/ or carotid artery obstruction/ or carotid artery thrombosis/ or internal carotid artery occlusion/ or brain infarction/ or brain infarction size/ or brain stem infarction/ or cerebellum infarction/ or exp brain ischemia/ or exp occlusive cerebrovascular disease/ or stroke patient/

2. ( (brain or cerebr\$ or cerebell\$ or vertebrobasil\$ or hemispher $\$$ or intracran $\$$ or intracerebral or infratentorial or supratentorial or middle cerebr\$ or mca\$ or anterior circulation) adj5 (isch?emi\$ or infarct\$ or thrombo $\$$ or emboli\$ or occlus\$ or hypoxi\$)).tw.

3. (isch?emi\$ adj6 (stroke\$ or apoplex\$ or cerebral vasc\$ or cerebrovasc\$ or cva or attack\$)).tw.

4. 1 or 2 or 3

5. exp Low Molecular Weight Heparin/

6. (low molecular weight heparin\$ or low-molecular-weight heparin\$ or Imwh\$).tw.

7. (antixarin or ardeparin or bemiparin or certoparin or cy 222 or dalteparin or embolex or enoxaparin or fondaparin\$ or idraparinux or monoembolex or nadroparin or parnaparin or rd 11885 or reviparin or tedelparin or tinzaparin).tw.

8. heparinoid/

9. (heparinoid\$ or atheroid or danaparoid or org 10172 or mesoglycan or dermatan sul\$ or heparan sul\$ or pentosan polysul\$).tw.

10. or $/ 5-9$

11.4 and 10

\section{Appendix 4. Trials registers}

The following registers were searched with the terms heparin AND stroke

- ClinicalTrials.gov (clinicaltrials.gov/)

- EU Clinical Trials Register (clinicaltrialsregister.eu/ctr-search/search)

- Stroke Trials Registry (strokecenter.org/trials/).

- ISRCTN Registry (isrctn.com/)

- WHO International Clinical Trials Registry Platform (who.int/ictrp/en/)

\section{FEE D B A C K}

\section{Feedback on the 2004 version of this review}

\section{Summary}

If unfractionated heparin (UFH) does not benefit patients with acute ischaemic stroke, why do a review where UFH is the control intervention? Although low-molecular-weight heparins/heparinoids (LMWH) do not reduce death or disability (but do increase intracranial bleeding), should the 'Implications for practice' justify LMWH in some case of acute ischaemic stroke in view of their reduction of deep vein thrombosis (and probably pulmonary embolism) in comparison with UFH? Similarly, are further trials of anticoagulant ethical?

\section{Reply}

The first version of the review was prepared at a time when there was uncertainty about the overall effects of heparins in acute ischaemic stroke. Since then, as the commenter states, evidence has emerged which shows that there is no net benefit from the immediate anticoagulation in this setting. However, as is often the case, this evidence did not alter the beliefs of some clinicians, and hence, heparin is still used in some countries, in certain types of patient with acute ischaemic stroke, for specific reasons and especially for prevention of venous thrombo-embolism. 
This review is now based on the premise that if a clinician plans to treat a patient for some special reason with some form of heparin then the choice of agent should be evidence based. The wording of the 'Implications for practice' and 'Implications for research' sections reflect this.

I should point out that this review is currently being updated, and we have identified three further trials comparing LMWH with UFH in acute stroke, which testifies to the belief among some clinicians in the value of this form of treatment. The emergence of new evidence is a good reason to keep the review up to date.

\section{Contributors}

Commenter: David K Cundiff, MD (22 June 2007)

Reply: Professor Peter Sandercock (9 July 2007)

\section{WHAT'S NEW}

\begin{tabular}{lll}
\hline Date & Event & Description \\
\hline 8 February 2017 & $\begin{array}{l}\text { New citation required but conclusions } \\
\text { have not changed }\end{array}$ & Conclusions not changed. \\
\hline 8 February 2017 & New search has been performed & $\begin{array}{l}\text { New author added. Searches updated. Background section re- } \\
\text { vised, updated and new references added. Primary objective for } \\
\text { review and primary outcome defined. Searches updated, PRIS- } \\
\text { MA diagram added. We identified no new studies: the review has } \\
\text { nine included studies involving 3137 participants. We have edit- } \\
\text { ed and updated the text and added 'Risk of bias' tables and a } \\
\text { 'Summary of findings' table. }\end{array}$ \\
\hline
\end{tabular}

\section{H I S T O R Y}

Protocol first published: Issue 1, 1995

Review first published: Issue 1, 1995

\begin{tabular}{lll}
\hline Date & Event & Description \\
\hline 7 March 2011 & Feedback has been incorporated & Link to feedback added. \\
\hline 28 July 2008 & Amended & $\begin{array}{l}\text { Previous feedback on the 2004 version of this review (published } \\
\text { in Issue 2, 2005) has been re-incorporated. See Feedback section. }\end{array}$ \\
\hline 14 March 2008 & Amended & Converted to new review format. \\
\hline 3 March 2008 & New citation required but conclusions & There has been a change in authorship. \\
\hline have not changed & New search has been performed & $\begin{array}{l}\text { We updated the searches to June 2007 and included three new } \\
\text { studies (TRACE 2004, PROTECT 2006, PREVAIL 2007) with 2397 } \\
\text { patients. The total number of included trials is now nine with } \\
\text { 3137 participants. The review has been edited extensively. }\end{array}$ \\
\hline
\end{tabular}

\section{CONTRIBUTIONSOF AUTHORS}

TL ran the searches, TL and PS selected studies, extracted data and wrote the revised text for this update 


\section{DECLARATIONS OF INTEREST}

Peter Sandercock: principal investigator of the International Stroke Trial. In the distant past, he received Honoraria (paid to the department) and travel expenses from a variety of pharmaceutical companies (including Organon) for giving lectures at medical conferences. He is not involved in any contractual consultancies with any company; he is not on the speakers panel of any company.

Tze Shin Leong: none known

\section{SOURCES OF SUPPORT}

\section{Internal sources}

- University of Edinburgh, UK.

\section{External sources}

- No sources of support supplied

\section{DIFFERENCES BETWEEN PROTOCOLANDREVIEW}

For this update, the Background was revised, updated and new references added. For consistency with other Cochrane Stroke Group reviews, we defined a single primary objective for the review and consequently selected a single primary outcome. The main search strategies were reviewed and search terms updated (Appendix 1; Appendix 2; Appendix 3; Appendix 4). No changes to the methods of analysis were required. A PRISMA diagram was added (Figure 1). We added funnel plots (Figure 4; Figure 5). We rechecked all included studies and evaluated the risk of bias for each study in greater detail. We added 'Risk of bias' tables. We also conducted GRADE assessment and included Summary of findings for the main comparison. The analytic methods did not change.

\section{INDEX TERMS}

\section{Medical Subject Headings (MeSH)}

Acute Disease; Anticoagulants [*therapeutic use]; Brain Ischemia [drug therapy]; Cause of Death; Fibrinolytic Agents [*therapeutic use]; Hemorrhage [chemically induced] [epidemiology]; Heparin [therapeutic use]; Heparin, Low-Molecular-Weight [ ${ }^{\star}$ therapeutic use]; Heparinoids [ ${ }^{*}$ therapeutic use]; Pulmonary Embolism [epidemiology]; Randomized Controlled Trials as Topic; Stroke [ ${ }^{\star}$ drug therapy] [mortality]; Venous Thrombosis [epidemiology]

\section{MeSH check words}

Humans 